\title{
Platelet-Cancer Interplay: Molecular Mechanisms and New Therapeutic Avenues
}

\author{
Attila Braun ${ }^{1}$, Hans-Joachim Anders ${ }^{2}$, Thomas Gudermann ${ }^{1}$ \\ and Elmina Mammadova-Bach ${ }^{1,2 *}$ \\ ${ }^{1}$ Walther-Straub-Institute for Pharmacology and Toxicology, Ludwig-Maximilian-University, Member of the German Center for \\ Lung Research (DZL), Munich, Germany, ${ }^{2}$ Division of Nephrology, Department of Medicine IV, Ludwig-Maximilians-University \\ Hospital, Munich, Germany
}

OPEN ACCESS

Edited by:

Martin Schlesinger,

University of Bonn, Germany

Reviewed by:

Paola Patrignani,

University of Studies G. d'Annunzio

Chieti and Pescara, Italy

Mirta Schattner,

Academia Nacional de Medicina

Argentina

${ }^{*}$ Correspondence:

Elmina Mammadova-Bach

e.bach@/rz.uni-muenchen.de

Specialty section:

This article was submitted to Molecular and Cellular Oncology,

a section of the journal

Frontiers in Oncology

Received: 08 February 2021 Accepted: 17 June 2021

Published: 12 July 2021

Citation:

Braun A, Anders H-J, Gudermann T and Mammadova-Bach E (2021)

Platelet-Cancer Interplay:

Molecular Mechanisms and

New Therapeutic Avenues.

Front. Oncol. 11:665534.

doi: 10.3389/fonc.2021.665534
Although platelets are critically involved in thrombosis and hemostasis, experimental and clinical evidence indicate that platelets promote tumor progression and metastasis through a wide range of physical and functional interactions between platelets and cancer cells. Thrombotic and thromboembolic events are frequent complications in patients with solid tumors. Hence, cancer modulates platelet function by directly inducing platelet-tumor aggregates and triggering platelet granule release and altering platelet turnover. Also, platelets enhance tumor cell dissemination by activating endothelial cell function and recruiting immune cells to primary and metastatic tumor sites. In this review, we summarize current knowledge on the complex interactions between platelets and tumor cells and the host microenvironment. We also critically discuss the potential of anti-platelet agents for cancer prevention and treatment.

Keywords: platelets, cancer, thrombosis, anti-platelet therapies, metastasis

\section{INTRODUCTION}

Cancer is caused by uncontrolled cell division and growth of malignant cells, which can spread throughout the body, resulting in metastasis $(1,2)$. For years, cancer biology focused on tumor cell attributes, leading to life-threatening complications. Initial studies on tumor suppressor genes and oncogenes fostered our understanding of the basic mechanisms of tumorigenesis and associated cell signaling pathways that lead to tumor cell malignancy. In recent years, many studies provided evidence that tumor progression is not tumor-cell autonomous, but rather involves cellular and molecular cross-talk with the different components of the surrounding tumor environment $(3,4)$. This tumor microenvironment is formed of complex tissues that contain extracellular matrix (ECM), cytokines, growth factors, and adhesion molecules, also diverse cellular components such as fibroblasts, immune cells, adipocytes, pericytes, epithelial cells, lymphatic and endothelial cells and platelets (5). Stimulated crosstalk between tumor and the surrounding environment involves the recruitment of various cell types, remodeling of the ECM, as well as stimulating the immune and 
coagulation system (6). The tumor microenvironment provides the necessary milieu, nutrients, and blood supply which stimulates tumor cell spreading and metastasis throughout the body.

Platelets are small anucleated fragments derived from megakaryocytes in bone marrow sinusoids, circulating in the blood, which play a critical role in thrombosis and hemostasis, arrest of bleeding in healthy conditions. Upon vascular injury, (i) the exposure of subendothelial matrix proteins to the blood flow, (ii) anchoring von-Willebrand-Factor (vWF) to the matrix and platelet surface, thereby (iii) inducing platelet glycoprotein (GP)Ib $\alpha-v W F$ interaction and subsequent (iv) GPVI-collagen interaction, are crucial steps in platelet adhesion and thrombus formation $(7,8)$. Platelets express several integrins on the surface, which interact with various ligands, including fibrinogen, vitronectin, collagen, fibronectin, and laminin, which mediate platelet attachment to the vessel wall. In secretory granules, platelets store several bioactive plasma proteins (coagulation factors, fibrinogen, vWF), regulatory factors and secondary mediators, such as adenosine di- and triphosphate (ADP/ATP) and serotonin, which are released upon platelet activation, thereby enhancing pro-thrombotic events, stimulating the recruitment of circulating platelets to the site of injury $(8,9)$. Platelet accumulation at the site of vascular injury triggers platelet aggregation and blood clotting, generating thrombin and active coagulation factors. This process is regulated by the extrinsic and intrinsic coagulation pathways. Upon the action of thrombin, soluble fibrinogen is converted to fibrin, which enhances platelet activation and aggregation responses. Activated platelets expose phosphatidylserine (PS) facilitating the recruitment of the prothrombinase complex, thereby connecting the outer platelet surface to components of the coagulation cascade (9-11).

Thrombotic events have been frequently observed in cancer patients indicating an active involvement of platelets and factors released from platelets in tumor progression, enhancing procoagulant activity and blood clotting $(12,13)$. Although the systemic effects of platelets in thrombotic complications of cancer patients have been described, compelling experimental and clinical evidence linked platelet function to tumor angiogenesis, tumor progression and metastasis through the interaction of platelets with cancer cells and tumor microenvironment. However, the direct involvement of platelets in the tumor-forming microenvironment has not yet been convincingly demonstrated (14). Several open questions have to be answered before we can begin to understand the molecular mechanisms of platelet-dependent tumor growth and metastasis. In the first part of this review, we summarize several concepts that we described in 2015 (14) by presenting new experimental and conceptual progress about the role of platelets in different steps of tumor progression, including the molecular mechanisms of cancer-associated thrombosis and thrombo-inflammation, tumor angiogenesis and metastasis. In the second part of our review, we discuss the advantage of the clinical diagnosis of platelet-related molecular and cellular signatures and highlight anti-platelet therapies to avoid hemostatic complications in cancer patients, and to increase the efficacy of anti-cancer therapies.

\section{CANCER-ASSOCIATED THROMBOSIS AND THROMBO-INFLAMMATION}

Cancer patients often suffer from thrombotic complications, such as deep vein or arterial thrombosis, and pulmonary emboli. Thromboembolic disease is the second leading cause of death in cancer patients diagnosed with obesity, leukocytosis, anemia or thrombocytosis. Thrombocytosis is associated with poor survival and increased risk of tumor metastasis and venous thromboembolism (VTE) in a wide variety of cancers, including colorectal, breast, lung, renal and gastric cancers (15-18). Depending on the disease state of cancer, patients have to face a 4 to 8 times greater risk of venous thrombosis or thromboembolism compared to patients without cancer (18). However, the exact molecular mechanisms of thrombocytosis and other aforementioned pathological complications are only partially understood. Approximately one-third of newly diagnosed ovarian cancer patients have exceedingly high platelet counts that are associated with shortened survival (19).

Several studies suggested a molecular mechanism of the development of cancer-associated thrombocytosis which can be explained by the ability of some cancer cell types to produce thrombopoietin (TPO), a key cytokine stimulating megakaryocyte differentiation and proliferation and resultant platelet production. Elevated serum levels of TPO were observed in cancer patients with reactive thrombocytosis (19, 20). Interestingly, in many cases, cancer patients with high plasma levels of TPO also had increased production of interleukin (IL)-6, and both parameters were linked to advanced disease and poor survival $(19,21)$. Accordingly, in mouse models of colorectal and ovarian carcinoma, the inflammatory response of tumor and immune cells involves IL- 6 production that can stimulate platelet production by enhancing TPO secretion from hepatocytes $(19,22)$. This pathological process is inhibited in IL-6-deficient mice, confirming the paraneoplastic effect of IL-6 in colorectal carcinoma-induced thrombocytosis (22). Additionally, ovarian cancer cells can secret functionally active TPO, directly affecting platelet production in the bone marrow (23). Besides thrombocytosis, cancer patients present with elevated expression of platelet-derived markers, including CD40 and $\beta$ thromboglobulin (24). P-selectin exposed on the activated platelet surface and soluble form are increased in the blood, and this increased level was associated with VTE in cancer patients (24-26). Moreover, cancer patients frequently have high levels of CD63-positive platelet-derived microparticles (PMPs), inducing a pro-coagulant cancer environment

(Figure 1) $(27,28)$.

Cancer cells can directly activate platelets and enhance thrombus formation. Tumor cell-induced platelet activation and aggregation (TCIPA) has been detected in vitro using neuroblastoma, small-cell lung, fibroblastoma, renal, gastric, 


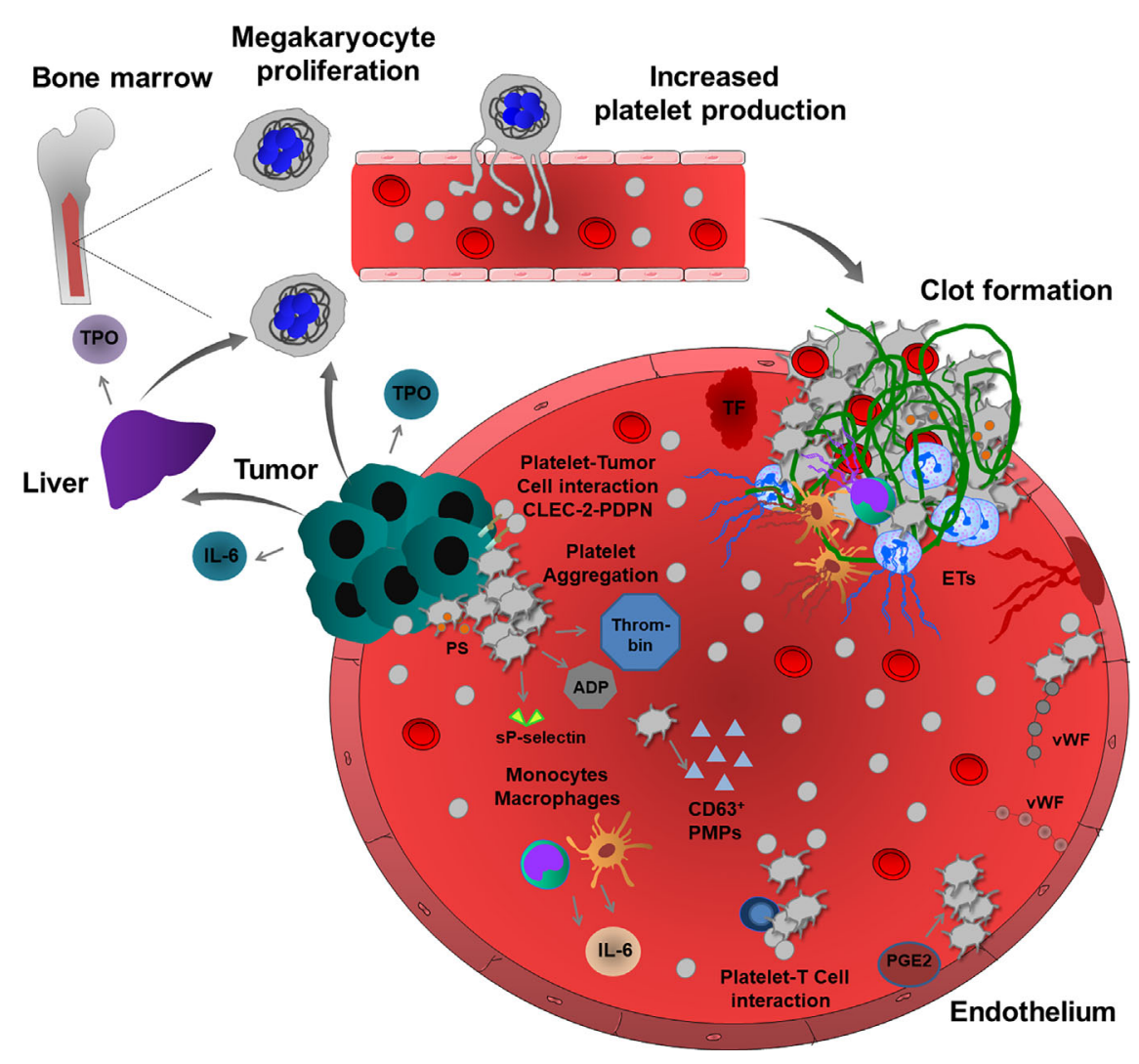

FIGURE 1 | Cancer-associated thrombosis and thrombo-inflammation. Growing tumors can induce thromboembolic events through several mechanisms. Tumor and immune cells (monocytes and macrophages) release inflammatory cytokines, such as IL-6, which regulate TPO levels in the liver, thereby enhancing the proliferation of megakaryocytes and consequent platelet production. Some tumor cells can also produce TPO, thereby increasing platelet production. In a prothrombotic tumor environment, TF and platelet and endothelial cell-derived vWF enhance platelet activation and aggregation. CLEC-2-PDPN-mediated interactions enhance platelet-tumor cell cross-talk and TCIPA. Activated platelets release many pro-coagulant factors and also sP-selectin and ADP. Increased thrombin generation and PS - exposure on the surface of activated platelets induce intravascular clotting and thrombosis. In addition, platelets and tumor microenvironment activate immune cells, such as neutrophils, monocytes, macrophages and also endothelium thereby promoting the release of ETs, further inducing inflammation, platelet activation, aggregation and fibrin-rich clot formation. During cancer progression, platelets also interact with $T$ cells to enhance thrombosis. In addition, endothelial PGE2, PMPs and extracellular vesicles can also enhance platelet activation and induce thrombosis and thrombo-inflammation in growing tumors.

melanoma, breast and colorectal cancer cells (29). Cancer cellresident podoplanin (PDPN) was proposed as a key regulator of this process. PDPN is a type I transmembrane sialomucin-like glycoprotein located on the surface of many tumor cells, including squamous cell carcinoma, seminoma and brain cancer cells (30). Increased expression of PDPN in cancer cells is associated with a high risk of thrombosis (30). Overexpression of PDPN in vascular endothelial cells could also induce thrombo-inflammation, possibly promoting PDPN-induced cellular interactions between platelets, cancer cells and endothelial cells. Platelet aggregation was enhanced by PDPNpositive oral squamous carcinoma cells, and mice developing PDPN-positive tumors have a reduced survival rate (31). Podoplanin expression by human brain tumors also induces platelet aggregation and is associated with hypercoagulability and a high risk of VTE (32). C-type lectin-like receptor-2 (CLEC-2) was originally discovered as an important platelet hemiimmunoreceptor tyrosine-based activation motif (ITAM) receptor, which is activated by snake venom toxin rhodocytin and PDPN. Inhibition of platelet CLEC-2 function in a mouse model of lung cancer significantly reduces thrombus formation and metastatic events after injection of B16F10 melanoma cells, suggesting that interaction between platelet CLEC-2 and cancerresident PDPN may also enhance thromboembolism, TCIPA and platelet-dependent tumor cell spreading in human patients (33).

Cancer cells can also trigger indirect platelet activation by enhancing the release of ECM proteins and tissue factor (TF) from endothelial cells, building an active surface for platelet adhesion and thrombus formation (34). Platelet-dependent thrombin generation and consequent protease-activated receptor (PAR) activation, phospholipase C (PLC) activation, calcium store depletion, and activation of the small guanosine-5'triphosphate (GTP)-ase Rap1b signaling have been detected in this process. Inhibition of PLC in platelets could prevent TCIPA, indicating the major route of inositol trisphosphate $\left(\mathrm{IP}_{3}\right)$ dependent calcium store release and diacylglycerol (DAG)mediated signaling in this process, probably acting on DAG/ 
protein kinase $\mathrm{C}(\mathrm{PKC})$-mediated Rap1b activation (35). $\mathrm{IP}_{3^{-}}$ dependent calcium store release also induces PS exposure on the platelet surface, activating the prothrombinase complex. In line with this, PS-positive platelets were found to be significantly higher in the blood samples of cancer patients, resulting in shorter blood clotting time and increased prothrombinase activity $(28,36)$.

Cancer-associated thrombosis can be induced independently of TF. Gas6 is a vitamin K-dependent ligand for the receptor tyrosine kinase family comprising Tyro3, Axl and Mer (TAM), acting as pro-survival factors in both tumor and endothelial cells (37). Although Gas6 regulates inflammatory functions in immune and endothelial cells, in lung cancer cell-associated venous thrombosis model, Gas6 enhanced prostaglandin E2 (PGE2) secretion from the endothelium leading to platelet activation and venous thrombosis (37). The interactions of platelets with $\mathrm{T}$ cells also contribute to an inflammatory procoagulant phenotype and thrombosis in patients with lung cancer (38).

The inflammatory response often results in increased levels of vWF released by activated platelets and endothelial cells, e.g. in post-operative patients with malignant prostate cancer (39). The thrombogenic lesions also increase the risk of TCIPA after surgical intervention (39). Interestingly, deficiency or inhibition of androgen receptor function in prostate cancer cells could induce TCIPA in vitro (40). Conclusively, the loss of androgen receptors in cancer cells accounted for the increased thrombogenicity, due to the enhanced expression of prothrombin. In sharp contrast, androgen receptor-positive prostate cancer cells cannot induce TCIPA (40). Mitrugno et al. reported that Fc $\gamma$ RIIa expressed on human platelets can mediate P3 prostate cancer cell-induced platelet activation and that these tumor cells directly induce ADP release (41). Interestingly, this platelet-tumor cell crosstalk is also induced by direct interaction of platelet Fc $\gamma$ RIIa with cancer cell-derived immunoglobulin G (42).

Neutrophil extracellular trap (NET) formation is frequently observed in cancer patients, increasing levels of histones, deoxyribonucleic acid (DNA), and other nucleosome compounds in the blood. NET release is associated with the incidence of cancer-associated thrombosis and organ failure, mainly triggering cancer-related coagulopathy (43). NET release was proposed as a causative factor in pancreatic cancer and more than $25 \%$ of cancer patients develop VTE (44). Increased levels of TF, extracellular vesicles, citrullinated histone $\mathrm{H} 3$ and extracellular vesicle TF activity were observed in these patients. Using different in vivo experimental settings, inhibition of TF, depletion of neutrophils, or administration of deoxyribonuclease I (DNAse I) in mice could inhibit venous thrombosis (45). These results suggest that systemic DNAse I treatment degrading NETs can inhibit cancer-associated thrombosis and tumor growth. Interestingly, in many experimental models, DNAse I treatment, but not neutrophil depletion could inhibit tumor growth and thrombosis, indicating alternative sources of ETs (46-50). Increasing evidence suggests that monocytes, macrophages and endothelial cells can also extrude their granular and nuclear content and in some cases, activated platelets contribute to the process of ETosis $(48,50-$ 52). Pro-coagulant cancer cells can also release ETs (53). Altogether, these results suggest that platelets and their granular content may contribute to the formation of ETs, supporting thrombus formation and coagulopathy in cancer patients.

\section{PLATELETS AND VASCULAR NETWORK OF TUMORS}

\section{Vascular Sprouting}

After reaching a certain size, solid tumors need to stimulate angiogenesis, receiving more nutrients and growth factors, which are required for energy metabolism, signaling and tumor growth (54). Tumor angiogenesis includes vessel sprouting, intussusceptive endothelial cell growth, remodeling and differentiation into arterioles, venules and capillaries. Vascular sprouting is a tightly regulated process involving the action of motile tip cells at the leading edge, that migrate towards proangiogenic signals and guided by pro-angiogenic vascular endothelial growth factor (VEGF) and proliferating stalk cells, elongate vascular sprout and generate the vessel lumen. This fully formed vessel recruits mural cells, pericytes and vascular smooth muscle cells, and promotes vessel integrity and blood perfusion (54).

Platelet $\alpha$-granules are the major store of the angiogenic factors that simultaneously control hemostasis and angiogenesis in the tumor microenvironment (55) (Figure 2). Activated platelets release $\alpha$-granule-resident pro-angiogenic factors, such as VEGF, epidermal growth factor (EGF), basic fibroblast growth factor (bFGF) and also release anti-angiogenic factors, such as angiopoietin-1 (ANGPT1), sphingosine 1phosphate (S1P), thrombospondin-1 (TSP1) and endostatin. Depending on external stimuli, platelets can selectively release these factors to stimulate or inhibit vessel formation in the growing tumor. For instance, ADP-stimulated platelets can release VEGF, but not endostatin, while thromboxane $\mathrm{A}_{2}$ $\left(\mathrm{TxA}_{2}\right)$ stimulation induces more endostatin release than VEGF in vitro conditions (56). ADP-stimulated plateletreleasate promotes the capillary formation of human umbilical vein endothelial cells (HUVEC), while thromboxane $\mathrm{A}_{2}$ $\left(\mathrm{TxA}_{2}\right)$-stimulated platelet-releasate inhibits this process (56). Platelet granule release may have anti-angiogenic effects in the tumor microenvironment, because higher endostatin, TSP1, angiostatin levels were measured in serum and urine of different cancer patients (57-59). However, the concept of co-clustering of proteins in distinct granules and differential granule release was challenged by several studies using quantitative enzyme-linked immunosorbent assay (ELISA), confocal immunofluorescence microscopy and proteomic approaches (60-64), which did not observe any functional pattern. Recently, it has been proposed that Stimulated Emission Depletion (STED) imaging can be applied to study platelet granule content and protein clustering in a more precise 


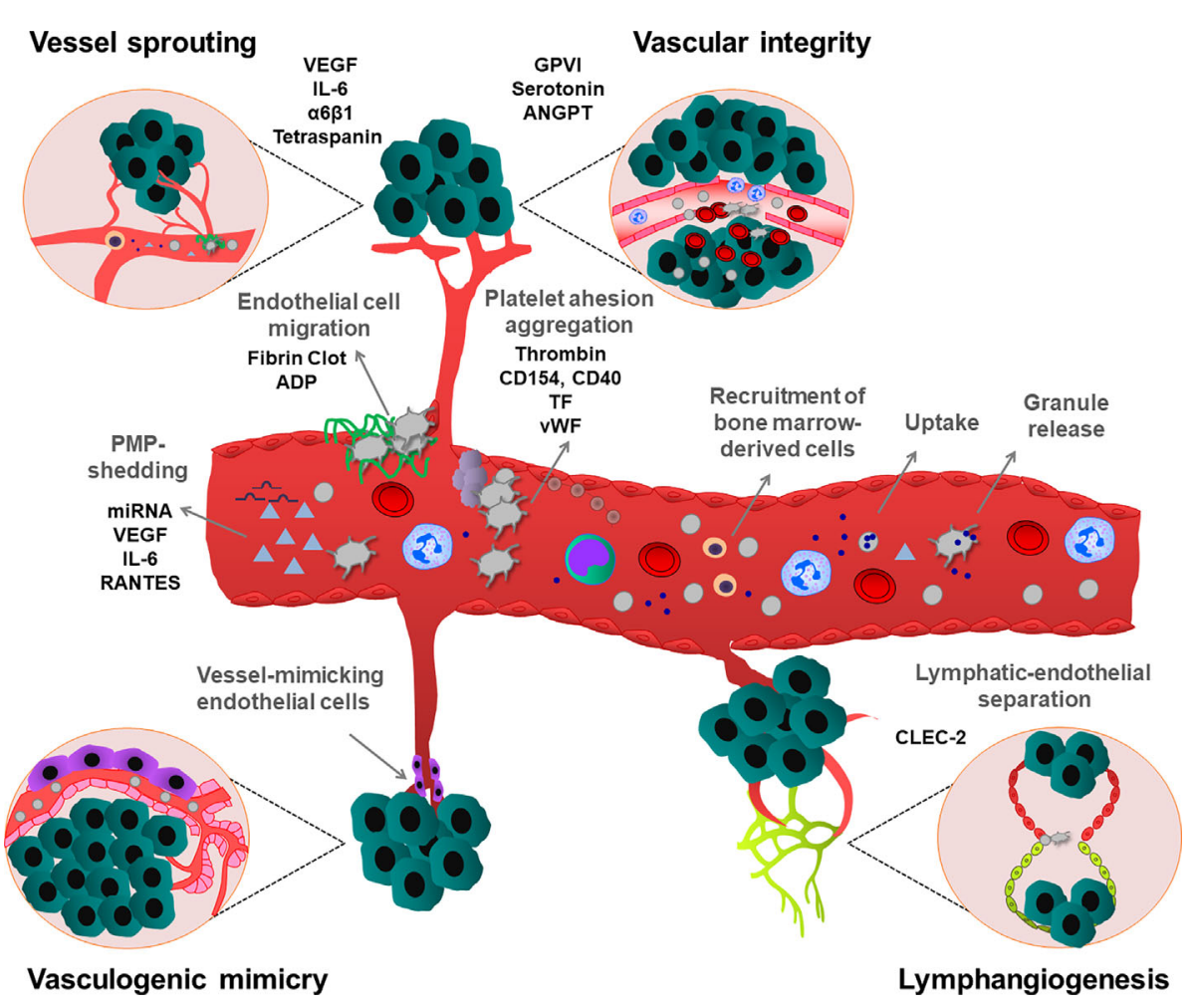

FIGURE 2 | Effects of platelets on different types of tumor angiogenesis and maintenance of vascular integrity. Platelets stimulate tumor neovascularization by multiple mechanisms. Platelets induce secretion of pro-angiogenic growth factors, from tumor and tumor microenvironment. Platelets can also uptake and sequester pro-angiogenic mediators from the tumor and surrounding environment and deliver and release them into the tumor. Additionally, PMPs enhance vessel formation. Platelets also stimulate the recruitment of bone marrow-derived cells to the angiogenic tumor tissues. Platelets attach to activated endothelium, thereby inducing the migration of endothelial cells on a platelet-rich fibrin matrix. Besides, platelets can maintain the integrity of tumor vessels, preventing hemorrhages, thereby enhancing the survival of growing tumors. Platelets also maintain the lymphatic-endothelial separation during tumor lymphangiogenesis. In contrast to their activatory roles in other angiogenesis types, vasculogenic mimicry-induced tumor angiogenesis is inhibited by platelets. As shown, all these processes can be regulated by plateletmediated processes involving different cellular and molecular mediators.

manner $(65,66)$. Whether depending on the time course and the activating stimuli, platelets can enhance or inhibit tumor angiogenesis by selective release of pro- or anti-angiogenic factors is an intriguing question, which needs to be addressed in an in vivo context.

Tumor cells can secret VEGF and platelets isolated from cancer patients selectively uptake and store VEGF in $\alpha$-granules. However, depending on the pathological conditions, cancer cells can also stimulate the release of platelet-resident VEGF, thereby regulating the local VEGF concentrations in the tumor microenvironment, which strongly influences tumor angiogenesis. Tumor-derived IL-6 increases VEGF expression in megakaryocytes, and consequent platelet VEGF levels also increased in platelet $\alpha$-granules, suggesting a complex interplay between platelets and cancer cells in the regulation of tumor angiogenesis (67).

In tumor xenograft and ischemic hind limb hypoxia models, platelets promoted the homing of bone marrow-derived cells to the neovascularized hypoxic tissues. This process was dependent on platelet granule releseate, containing growth factors and cytokines (68). In the xenograft breast cancer model, platelets sequestered cytokines released by human luminal breast cancer cells and delivered them to indolent tumors, thereby ensuring tumor outgrowth during angiogenesis (69).

Tumor-derived VEGF mediates endothelial cell activation, vWF release, and platelet aggregation thereby provoking the coagulation cascade in patients with melanoma cancer (70). vWF release was accompanied by local inhibition of proteolytic activity and protein expression of vWF cleaving protease ADAMTS13, (a disintegrin-like and metalloproteinase with thrombospondin type I repeats 13). VEGF can also enhance TF expression in the endothelium and inflammatory cells, which further increases platelet adhesion and thrombin generation (71). Accumulation of activated platelets was also observed on the fibrinogen/fibrin-coated endothelial surface. In turn, this provisional fibrin matrix supports endothelial cell survival and migration (72). Interestingly, the platelet $\delta$-granule-resident ADP, which was not critical for vessel formation, could facilitate endothelial cell migration (73).

Besides platelet-releseate, platelets possibly regulate angiogenesis independently of their granular content. Platelets can promote tube formation of HUVEC in a matrigel assay and this process was enhanced by direct contact between platelets and endothelial cells (74). Using a monoclonal antibody c7E3 
Fab (abciximab, ReoPro), inhibiting integrin $\alpha \operatorname{IIb} \beta 3$ function on the platelet surface, the platelet-enhanced capillary formation was reduced during tumor growth, hypoxia-induced retinal angiogenesis, and also in HUVEC in vitro $(75,76)$. Recent studies demonstrated that platelet tetraspanin could promote endothelial colony-forming culture tube formation (77). Tetraspanin function is also linked to laminin-specific integrin $\alpha 6 \beta 1$, since blockade of this type of integrin in both platelets and endothelial cells could attenuate the ability of platelets to promote tube formation (77). In similar conditions, platelet CD154 and endothelium-resident CD40 receptors further enhance platelet aggregation and thrombus formation $(71,78)$.

Activated platelets shed PMPs which are vesicular fragments with a size of 0.05 to $1 \mu \mathrm{m}$. PMPs contain several receptors and proteins on the membrane surface, including P-selectin and integrins, and store many growth factors, cytokines and inflammatory molecules $(79,80)$. Elevated PMP levels were detected in the plasma of cancer patients (81). Interestingly, PMPs could induce angiogenic effects to a similar extent as whole platelets. Increasing levels of VEGF, IL-6 and Regulated on Activation Normal T Cell Expressed (RANTES) were detected in PMPs isolated from patients with gastric cancer suggesting that PMP-shedding contributes to tumor angiogenesis (82). Platelets and PMPs also contain different types of miRNAs. Transferring of PMP-specific miRNA let-7a or miR-27b into endothelial cells could inhibit the expression of TSP1, thereby enhancing platelet-dependent endothelial tube formation $(83,84)$.

\section{Lymphangiogenesis}

Angiogenesis also occurs in lymphatic vessels, supporting tumor growth and dissemination. During embryonic development, platelets maintain the separated blood-lymphatic system by interacting with PDPN at the lympho-venous junction (85). In CLEC-2-deficient mice, lymphatic vessels were filled with blood, resulting in embryonic lethality (85). In the tumorigenesis model induced by intradermal injection of B16F10 melanoma cells, CLEC-2 deficiency was also associated with blood filling in lymphatic vessels (86). However, future studies are needed to evaluate the molecular mechanism, how platelet-resident CLEC2 can regulate lymphatic vessel separation during tumorigenesis.

\section{Vasculogenic Mimicry}

Vasculogenic mimicry occurs often in patients with aggressive cancer types, such as melanoma and cholangiosarcoma and possibly promotes tumor metastasis (87). Vascular mimicry reflects the ability of tumor or tumor stem cells to form vessellike networks for the obtention of oxygen and essential nutrients independently of sprouting angiogenesis (54). Interestingly, in contrast to other types of angiogenesis, platelets inhibit vasculogenic mimicry, indicating that platelets tightly coordinate the vascularization process, and may still potentiate tumor malignancy (88).

\section{Tumor Vascular Integrity}

Besides their pivotal role in angiogenesis, platelets regulate tumoral vascular integrity in primary tumors, thereby preventing tumor hemorrhages. Initial studies from Ho-Tin Noé et al. showed that the maintenance of tumor vascular integrity resulted in the secretion of platelet granular-resident serotonin and ANGPT, which stabilizes the structure of tumor blood vessels by counteracting with tumor-derived VEGF (89). By maintaining vascular integrity, platelets could reduce tissue damage, which was caused by tumor-infiltrating immune cells $(90,91)$. Later, it was proposed that tumor vessel destabilization might have beneficial effects, promoting effective delivery of chemotherapeutic agents into growing tumors (92). Recent studies showed that tumor vessel integrity depends on plateletspecific receptor GPVI and blocking this receptor in primary prostate and breast cancer tumors could increase the efficacy of chemotherapy (91). Although these studies highlighted the role of platelets and GPVI in the maintenance of tumor vessel integrity, the underlying molecular mechanisms remain elusive.

Depending on the disease context, platelets could regulate neovascularization, leading to the generation of permeable vessels. On the other hand, platelets could also induce vessel stabilization by maintaining vessel integrity, and in some cases, facilitated vessel maturation $(93,94)$. Compelling experimental and clinical pieces of evidence showed the heterogeneity and plasticity of the tumor and host cells. Growing tumors need a specific organization and structure of tumor vasculature. Platelets are the major cellular regulators of this process. Targeting tumor angiogenesis is an important concept in cancer research, which led to the development of antiangiogenic therapeutic strategies. However, the beneficial effects of anti-angiogenic therapies are often limited, due to several factors expressed by the tumor, inducing diverse celltype-specific resistance mechanisms (95). Hence, platelets regulate many functions of tumor vasculature, it is tempting to speculate that targeting platelet-mediated pathways in angiogenesis would be considered as an alternative antiangiogenic strategy.

\section{PLATELET FUNCTIONS IN TUMOR METASTASIS}

Invasive tumor cells that are detached from primary tumors can migrate and colonize and proliferate at distant sites, thereby forming secondary tumors, called metastases. Invasive cells entering into the vascular or lymphatic system undergo various shear and oxidative stress, also cytotoxic effects of immune cells, thereby reducing the number of cancer cells in the peripheral blood. However, a few numbers of tumor cells can escape from these processes, extravasate from vessels and colonize distant organs $(96,97)$. During this transit in the circulation, platelets are the first cells that encounter tumor cells, thereby supporting their metastatic potential. Several molecular mechanisms have been described in platelet-mediated steps of tumor metastasis (Figure 3). First experimental evidence was described by Gasic et al., who showed that thrombocytopenia was correlated with reduced metastasis and transfusion of platelets into the thrombocytopenic mice restored the capacity to form 


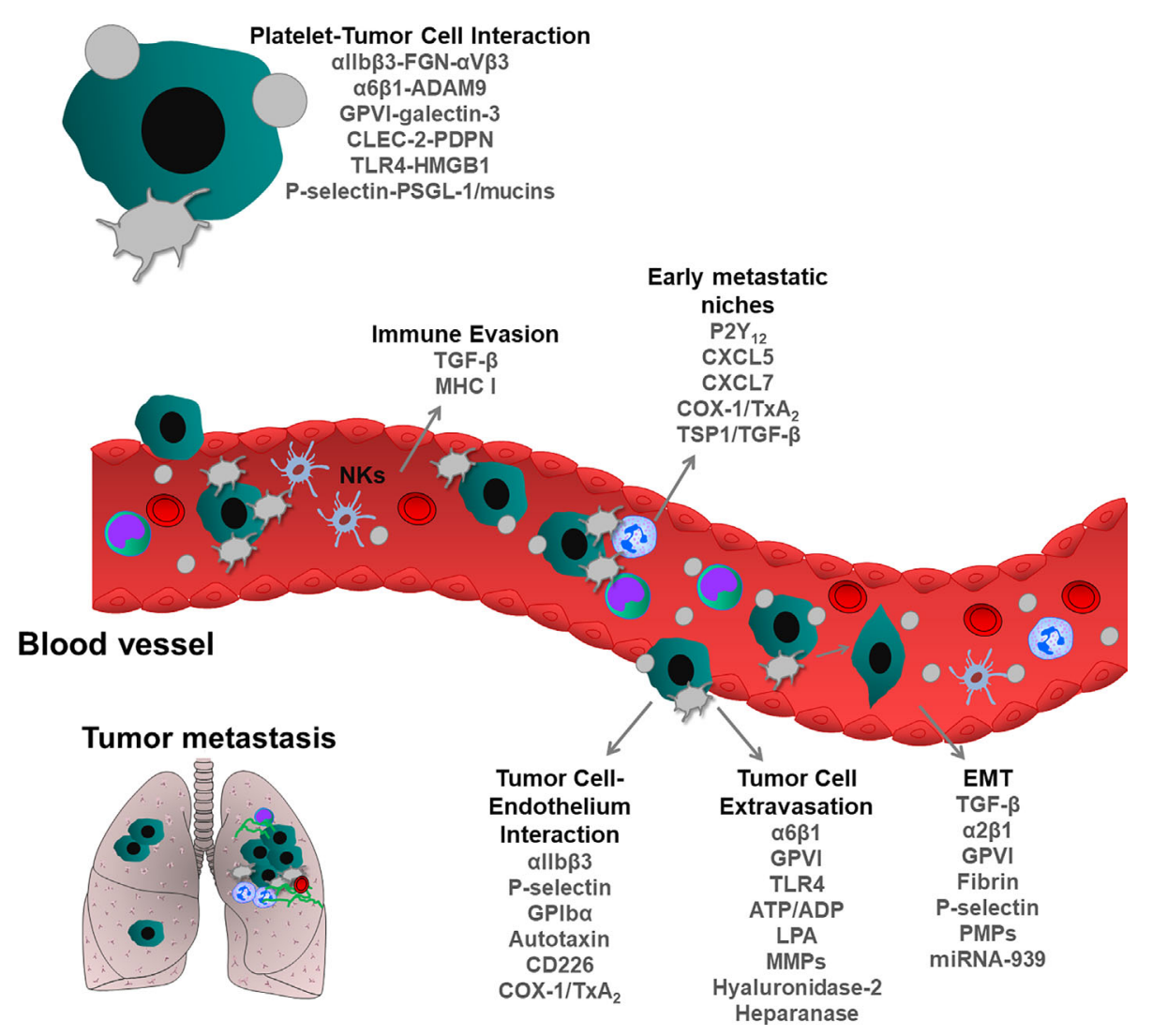

FIGURE 3 | Role of blood platelets in tumor metastasis. During metastatic spread, tumor cells enter into the blood circulation where they encounter tumor cells. Physical and functional interactions between platelets and tumor cells support metastatic dissemination of tumor cells and survival at distant metastatic organs. Platelets protect tumor cells from immune system surveillance, thereby enhancing the survival of circulating tumor cells. Following interactions with platelets, epithelial cancer cells can acquire mesenchymal phenotype, rapidly invading distant organs. Platelets form an active complex with inflammatory and tumor cells within the vasculature, thereby supporting the formation of metastatic niches. Platelets also can directly bridge tumor cells to the endothelium and induce their extravasation, leading to the seeding and proliferation of metastatic cells. As shown, each step of metastatic cascade is regulated by platelet-resident receptors and or other platelet-derived bioactive molecules, such as growth factors, cytokines, chemokines and miRNA.

metastases (98). In line with this, later studies described that impaired megakaryopoiesis and platelet production also reduce metastatic events in different mouse models (99).

\section{Platelets and Immune Evasion of Cancer Cells}

From all the cancer cells that enter into the circulation, only a small number forms metastatic foci $(96,100)$. Besides shear stress, cytotoxic natural killer (NK) cells eliminate most cancer cells from circulation. Platelets are the first blood cells to interact with cancer cells and serve as a physical ring to protect cancer cells from immune system surveillance (96). Studies inducing thrombocytopenia in mice suggest that platelets impact NK cellmediated lysis of tumor cells (101) and this hypothesis was followed by Palumbo et al., using fibrinogen or Goq proteindeficient mice and their mutant platelets (102). In both cases, cancer cell survival was strongly reduced. These studies proposed that activated platelets together with fibrinogen (or fibrin) could cover cancer cells and protected them from NK cell-induced killing mechanisms (102). However, others showed that platelets exert their pro-metastatic effects within the first hour following the entry of tumor cells into the circulation, whereas antimetastatic effects of NK occur between 1 and 6 hours after tumor cell intravasation (103). During interactions with tumor cells, platelets transfer major histocompatibility complex (MHC) class I molecules on tumor cells, thereby providing a self-signal to NK cells to inhibit their killing activity in vitro (104). In addition, platelet-mediated shedding of Natural Killer Group 2D (NKG2D) ligands could also inhibit this cytotoxic effect of NK cells (105). Platelets can store a significant amount of TGF- $\beta$ in $\alpha$-granules (50-100 times more than other blood cells) (106), and release it into the circulatory system (107) and tumor microenvironment (108) during cancer progression and metastasis. It has been shown that platelet-derived TGF- $\beta$ causes the downregulation of NKG2D on NKs upon interaction with cancer cells, inhibiting anti-tumor immunity (109). In line with this, the downregulation of NKG2D has been associated with elevated levels of TGF- $\beta$ in patients with colorectal and lung cancer (110). TGF- $\beta$-docking receptor glycoprotein A repetitions predominant (GARP) protein 
activates the latent form of platelet TGF- $\beta$ and this protein complex together with platelet-secreted lactate inhibited immune response against both melanoma and colon cancer (108). Using the TGF- $\beta$-GARP complex, platelets could directly inhibit $\mathrm{T}$ cell function in vitro and in vivo experimental conditions, and TGF- $\beta$ rich platelet releasate and lactate can suppress both CD4+ and CD8+ T cell activity (108). Interestingly, thrombin can contribute to immune evasion by cleaving platelet-bound GARP thereby activating latent TGF- $\beta$ (111). TGF- $\beta$ inhibitors, blocking peptides and aptamers are currently used in clinical trials of patients with solid cancers (112). Using adoptive T cell transfer, as a therapeutic approach to stimulate the immune system, has been proposed as a promising anti-cancer strategy (113). It worth postulating that inhibition of TGF- $\beta$ uptake by platelets could be a potential anti-cancer strategy enhancing protective immune pathways.

\section{Platelets and Cancer Cell Reprogramming}

Epithelial-mesenchymal transition (EMT) is an important developmental program, which can also occur during cancer progression. Epithelial cancer cells change their morphology as they lose contact with the basement membrane and form the primary mesenchymal cell layer through EMT (114). Interestingly, the process of EMT can be reversible and primary mesenchymal cells can also be transformed into epithelial cells, and vice versa. EMT is supported by immune and stromal cells, also cells derived from the tumor microenvironment as well as the component of the ECM (114). Numerous factors are involved in the regulation of EMT, such as TGF- $\beta$, Hepatocyte Growth Factor (HGF) and EGF receptor, and transcription factors (ZEB1/2, Snail, Twist and Tiam1). Interestingly, EMT-like events occur during the intravascular transit of cancer cells when platelets interact with them, and at this moment, platelets release EMT inducers. In platelet-treated cancer cells, mesenchymal markers Snail family transcriptional repressor-1, vimentin, $\mathrm{N}$-cadherin, fibronectin and matrix metalloproteinase 2 (MMP-2) are frequently upregulated, while the epithelial markers (E-cadherin, claudin-1) are downregulated (107). Activated platelets can release TGF- $\beta$ from $\alpha$-granules, switching cancer cells to a pro-metastatic EMT phenotype. Platelet-derived TGF- $\beta$ and platelet-tumor cell interaction activate the TGF- $\beta$ and nuclear factor kappa light chain enhancer of activated B cells (NF- $\kappa \mathrm{B}$ ) pathways in cancer cells, resulting in EMT phenotype and enhanced metastasis in vivo. In line with this, inhibition of NF- $\kappa \mathrm{B}$ signaling in cancer cells or ablation of TGF- $\beta$ expression only in platelets reduces metastasis in the lung (107). Altogether, these results suggest a direct link between platelet-resident TGF- $\beta$ and EMT formation (107). Recently, tumor necrosis factor receptorassociated factor (TRAF) family member-associated NF- $\kappa B$ activator (TANK)-binding kinase 1 (TBK1) was identified as a mediator of platelet-induced EMT. Downregulation of TBK1 expression in cancer cells impaired platelet-induced EMT, which is due to the suppression of NF- $\mathrm{KB}$ signaling, suggesting that platelet-derived factors induce EMT in synergy with NF- $\mathrm{KB}$ pathways (115). This regulation is quite complex since platelets can induce EMT independently of NF- $\kappa \mathrm{B}$ pathways. In ovarian cancer cells, platelet-derived TGF- $\beta$ increased the invasive potential of tumor cells and induced EMT by increasing the phosphorylation of SMAD Family Member 2 (Smad2) (116).

ECM components, which are secreted by either tumor or tumor surrounding microenvironment, were proposed to be involved in EMT. Collagen and heat shock protein 47 (Hsp47), a chaperone that facilitates collagen secretion and deposition, was found to be highly expressed during EMT (117). Hsp47 expression induced mesenchymal phenotypes and enhanced platelet accumulation, leading to lung retention and colonization of cancer cells. Platelet depletion could abolish Hsp47-induced cancer cell retention in the lung, suggesting that Hsp47 promotes cancer cell colonization by enhancing cancer cell-platelet interaction (117). Accordingly, blockade of collagen receptor GPVI and integrin $\alpha 2 \beta 1$ on the platelet surface could abolish Hsp47-induced platelet interaction with 4T1, MDA-MB-231 and MCF10A breast cancer cells, indicating an important role of these platelet receptors in EMT (117). When MCF7 breast cancer cells were cocultured with platelets, EMT formation was also observed, and this process was mediated through direct contact with cancer-resident $\alpha 2 \beta 1$ integrin, leading to the activation of the Wnt- $\beta$-catenin signaling pathway (118). During systemic inflammation, platelet-fibrinrich extravascular environment strongly activates intestinal inflammatory cells through $\alpha \mathrm{M} \beta 2$ integrin and this interaction can support the release of different cytokines and growth factors thereby further supporting EMT (119).

Cathepsin family members are proteases that are highly upregulated and secreted by different cancer cells. Cathepsins are mainly localized in endosomal or lysosomal vesicles and are also secreted, as soluble exo-enzymes, cleaving ECM components around the cancer cells, and activate or inactivate surface receptors by proteolytic cleavage (120). Interestingly, cathepsin $\mathrm{K}$ isoform could induce platelet aggregation, and supporting interaction with EMT-like cancer cells. This action is triggered by cathepsin-mediated PAR-receptor cleavage on the platelet surface (121). Hetero-aggregation of platelets with cancer cells induces P-selectin exposure and CD44 activation, which further enhances Hedgehog (Hdg)-signaling and also activates growth factors such as sonic hedgehog $(\mathrm{SHH})$, osteopontin (OPN), parathyroid hormone-related protein (PTHrP), and TGF- $\beta$ (121). PMPs also modulate EMT. Coculture of ovarian cancer cells with PMPs increases EMT (122). Overexpression or knockdown of PMP-specific miRNA-939 strongly enhances or inhibits EMT, respectively (122). PMP/miRNA-939 uptake by cancer cells was regulated by secretory phospholipase A2 type IIA (sPLA2-IIA), suggesting an important role for PMPs in the crosstalk between platelets and cancer cells during EMT (122).

\section{Platelet-Mediated Interactions of Circulating Tumor Cells With Vessels}

Platelets play an important role in cancer cell trapping to vascular endothelium, thereby enhancing extravasation and dissemination to distant organs. Cancer cells are rolling along the endothelium, and this movement is maintained by platelet 
integrin $\alpha \operatorname{IIb} \beta 3$ and P-selectin to form stationary adhesion (123). Consequently, genetic deficiency or blockade of $\beta 3$ integrin and P-selectin decreases cancer cell colonization in the lung (124, 125). P-selectin also binds mucins and P-selectin glycoprotein ligand-1 (PSGL-1) on the surface of tumor cells, mediating the interactions among platelets, leukocytes and endothelium (126, 127).

It has been hypothesized that exposure of $\mathrm{vWF}$ on the activated endothelial cell surface could also support the recruitment of platelet-cancer cell aggregates since genetic deficiency or antibody-mediated blockade of GPIb $\alpha$, a vWF binding receptor on the platelet surface could inhibit TCIPA, also platelet-tumor cell interactions with endothelial cells, and consequent lung metastasis $(128,129)$.

Tumor cell-resident integrin $\alpha \mathrm{V} \beta 3$ also supports tumor cell interactions with platelets, allowing the interaction with vasculature and inducing tumor metastasis (130-132). At the invasive edge of tumor cells, $\alpha \mathrm{V} \beta 3$ integrins colocalize with nectin-like molecule 5 (NECL5). NECL5 interacts with CD226 on the platelet surface, enabling tumor cell adhesion to the endothelial vasculature, thereby leading to tumor metastasis (132). $\alpha \mathrm{V} \beta 3$ integrin on breast cancer cells can bind to platelet-derived autotaxin which is stored in $\alpha$-granules and secreted into the vasculature upon platelet activation (133, 134). This process could induce early bone colonization and the progression of skeletal metastases in mice.

Although several tumor cell types adhere to the endothelium together with platelet aggregates and rapidly form thrombi, other cancer cells do not need platelets for increasing adhesion properties to the endothelium. Different models exist to group experimental pieces of evidence and explain platelet-dependent or -independent cancer cell adhesion. Cancer cells are rarely associated with platelets in the liver, rather directly bind the ECM, exposed by the discontinuous endothelium of the sinusoids $(135,136)$. Cell adhesion of leukemia cells was also independent of platelets and in the arterioles of pulmonary endothelium, thrombus formation was only observed at the later stage of metastasis (137). In other cases, treatment of mice with the thrombin inhibitor hirudin disrupted the interaction between cancer cells and platelets in the circulation, but this treatment did not affect cancer cell adhesion on the endothelium (138). Altogether, platelet-cancer cell interaction may support the intravascular arrest of cancer cells, thereby promoting rolling and static adhesion on the endothelium. However, the importance of platelet-cancer cell interactions with the vasculature strongly depends on the type of cancer cells and metastatic organs.

\section{Platelets in Dynamics of Tumor Cell Extravasation}

After cancer cell arrest in the microvasculature, tumor cells transmigrate through the endothelium to form metastases. Most of the cancer cells attack capillaries and arterioles during extravasation. The structural differences of these vessels determine cancer cell behavior to rupture vessel barriers and successfully extravasate the targeted organs (139). Therefore, it is important to understand the distinct molecular mechanisms of extravasation related to vessel types, thereby designing selective therapeutic approaches to prevent metastasis. Several models exist to explain this complex pathological process, (i) how cancer cells and platelets modify vascular permeability, and (ii) how the endothelial cell layer and the basal membrane are ruptured, thereby promoting cancer cell extravasation. Platelets may promote endothelial cell retraction and paracellular migration of tumor cells, although in many cases, this process can be regulated independently of platelets (6). Platelets can damage the endothelium layer, releasing inducers of necroptosis (140), also damaging ECM network, thereby enhancing the extravasation of the cancer cells. Here, we highlight some platelet-derived factors that contribute to different stages of cancer cell extravasation.

Molecules stored in $\alpha$ - and $\delta$-granules can regulate vascular permeability. Upon activation, degranulated platelets release serotonin, VEGF, platelet-activating factor (PAF), thrombin, ATP/ADP, HGF, fibrinogen, which can potentially induce vascular permeability, and consequently promote cancer cell transmigration $(71,97)$. Studies showed that the extravasation of cancer cells into the lung parenchyma was reduced in Unc13d (Munc-13-4) knockout mice, in which platelet $\delta$-granule secretion was severely, and $\alpha$-granule secretion was moderately inhibited (141). Platelet-derived ATP induces the relaxation of endothelial junctions and vascular permeability by activating $\mathrm{P}_{2} \mathrm{Y}_{2}$ purinergic receptors on the surface of endothelial cells, and this process consequently was inhibited in $\mathrm{P}_{2} \mathrm{Y}_{2}$ knockout mice (141). Recently, we identified a novel molecular mechanism that further supports ATP-mediated effects in cancer cell metastasis. We showed that galectin-3 expressed on the surface of colon and breast cancer cells interacted with platelet-specific receptor GPVI and this receptor-ligand mediated cellular crosstalk could enhance platelet activation and degranulation (ATP secretion) which further support tumor cell extravasation (142). In line with previous studies, impaired $\delta$-granule release and apyrasemediated blockade of ATP function in platelets, strongly inhibited endothelial transmigration of tumor cells, indicating an important role of platelet-derived nucleotides in this process $(141,142)$.

Serotonin is a biogenic monoamine produced from tryptophan. Serotonin synthesis takes place in the enterochromaffin cells, located in the gastrointestinal tract, that release serotonin into the blood, where platelets rapidly take it up into $\delta$-granules (143). Local accumulation of serotonin modulates the vascular tone thereby influencing sheardependent processes. Circulating tumor cells increase the plasma levels of serotonin and blockade of serotonin receptors or calcium channels could effectively inhibit experimental liver metastasis, indicating multiple roles of serotonin in different steps of cancer progression (144). However, the role of plateletderived serotonin in tumor progression, including the extravasation stage, has not been investigated.

Activated platelets release lysophosphatidic acid (LPA) from their $\alpha$-granules, which can also induce tumor cell invasion and influence the permeability of the endothelium, thereby promoting transendothelial cell migration $(145,146)$. In line with this, lung 
metastasis was impaired in Neurobeachin-like 2 (Nbeal2) knockout mice lacking $\alpha$-granules (147). Blocking platelet activation leads to a decrease in LPA concentration in the blood. Autotaxin is a secreted glycosylated enzyme with lysophospholipase D (LPD) activity, which is responsible for the regulation of basal LPA levels in the blood (148). Interestingly, cancer cell-resident CD97/G-protein-coupled receptors (GPCR) can induce platelet activation thereby enhancing both LPA release from $\alpha$-granules and ATP secretion from $\delta$-granules (145). Consequently, this platelet releseate could increase tumor cell-induced vascular permeability and lung metastasis (145).

ADAM9 is a member of the disintegrin and metalloproteinase (ADAM) family, which induce the shedding of receptors (149). Interestingly, this proteinase can promote tumor cell migration and metastasis in both MMP-dependent and -independent manner (149-151). Interaction of platelet-resident $\alpha 6 \beta 1$ with the disintegrin-cysteine-rich domain of tumor cell-derived ADAM9 also triggers platelet activation, $\alpha$-granule release and P-selectin exposure, increasing tumor cell extravasation (150). Platelet-tumor cell interactions mediated by platelet toll-like receptor 4 (TLR4) and tumor cell-released high-mobility group box 1 protein (HMGB1) lead also to the $\alpha$-granule release and $\mathrm{P}$ selectin exposure, subsequently increasing the number of extravasating tumor cells in lung vessels (152).

To effectively cross the subendothelial layer, cancer cells should damage and move through the basement membrane. Platelets can store and release several exo-enzymes, such as MMPs, platelet hyaluronidase-2, and heparanase, that can degrade collagen-rich ECM components (153, 154). After platelet depletion, the reduced extracellular activity of MMPs was observed and consequently, the number of lung metastases was also reduced in mice, highlighting the contribution of platelet-derived MMPs in the degradation of the basement membrane (155).

Altogether, these studies suggest that platelets are involved in tumor cell extravasation, although only limited in vivo experiments showed the importance of platelet receptors and enzymes in the process of basement membrane degradation.

\section{Platelets and Metastatic Seeding}

During systemic inflammation, the release of ECM stimulates the environment of distant organs to accept tumor cell seeding, thereby actively enhancing tumor metastasis (156). Once tumor cells metastasized and formed certain tumor mass in host organs, evolved metastatic niches can again contribute to the recruitment of circulating blood and inflammatory immune cells $(156,157)$. In different steps of metastatic niche formation platelets are involved: (i) platelets can support cancer cell adhesion and granulocyte recruitment in the early metastatic niche, (ii) platelets can release different chemokines which stimulate the recruitment of host cells to build the tumor microenvironment, (iii) platelets also release pro-angiogenic factors at a later stage to induce local tumor vessel formation within the host microenvironment, (iv) platelets create an immune cell-rich environment around the developing metastases thereby supporting tumor cell proliferation and survival.
Growing tumors release angiogenic growth factors, allowing cancer cells to develop a niche before they metastasize. Tumor cell-derived VEGF alters the microenvironment of distant organs. VEGF triggers inflammation, also increases cyclooxygenase (COX) products and PGE2, leading to the homing of cancer cells to the lungs (158). Several ECM components, integrins and VEGF receptors have been identified as main regulators of organ-specific cancer cell tropism and niche formation (159). In line with this, platelet $\mathrm{ADP}$ receptor $\mathrm{P} 2 \mathrm{Y}_{12}$ induces the recruitment of VEGFR1+ bone marrow-derived cell clusters and fibronectin deposition, which creates a premetastatic niche, selectively promoting lung metastasis (160).

During tumor metastasis, monocytes and macrophages are recruited to the metastatic niches and support cancer cell seeding. Platelet-resident chemokines (CXC motif ligand (CXCL) 5 and CXCL7) have been shown to promote the early stage of the metastatic niche through activation of granulocytederived C-X-C chemokine receptor 2 (CXCR2) (161). When cancer cells interact with platelets, chemokines from platelet $\alpha$ granules are released which recruit granulocytes to the cancerplatelet aggregates thereby supporting the seeding of metastatic cells (161).

Fibrin-rich platelet aggregates also provide a provisory matrix that further supports metastatic seeding. Indeed, TF expressed in brain cancer cells induces the coagulation cascade that results in thrombin formation, subsequent platelet activation and fibrin formation (162). Impairment of macrophage function in Mac- or CD11-deficient mouse models inhibits tumor cell survival, suggesting that the recruitment of functional macrophages to the platelet-rich clots is essential for this process (162). $\mathrm{TxA}_{2}$ stimulates macrophage infiltration and cytokine release (163). Using an experimental metastasis model with B16F10 melanoma cells, Lucotti et al. showed that the platelet-specific COX-1/TxA pathway induces platelet-tumor cell aggregation, endothelial activation, tumor cell adhesion to the endothelium, and also recruitment of monocytes/macrophages, thereby promoting premetastatic niche formation in the lung (164).

On the other hand, depending on the developmental phase of cancer and environmental stimuli, immune cells and granulocytes could also induce cell death in metastatic cancer cells. Derivates of PC3 prostate and MDA-MB-231 breast cancer cells with poor metastatic capacity can recruit pro-metastatic Gr+ myeloid cells and generate a metastasis-refractory microenvironment by inducing the secretion of TSP1, which seems to inhibit lung metastasis (165). In contrast, platelet-resident TSP1 had the opposite effect on bone metastasis. Within the bone microenvironment, TSP $1 /$ TGF- $\beta$ axis is involved in the regulation of premetastatic niche formation and bone metastasis (166).

Therapeutic targeting of early stages of cancer, evolving metastatic soil, is important in cancer patients. It could be interesting to evaluate the platelet-derived protein signature and the presence of platelet-tumor-immune cell conjugates in cancer patient tissues can represent prognostic and diagnostic tools, thereby helping an earlier intervention. 


\section{THERAPEUTIC TARGETS}

Platelet adhesion, activation, and aggregation are tightly regulated at different steps of tumor progression, thereby influencing the coagulation cascade and thrombus formation in cancer patients. Integrins, glycoproteins, and many other signaling receptors on the platelet surface are involved in these processes. Below, we discuss the therapeutic effects on the function of the main platelet receptors and regulatory mechanisms controlling tumor progression and metastasis.

\section{Integrins}

Platelets express different integrins, including $\alpha 2 \beta 1, \alpha 5 \beta 1$ and $\alpha 6 \beta 1$, to facilitate the binding to collagen, fibronectin and laminin, respectively. Integrin $\alpha 2 \beta 1$ together with GPVI mediates direct interactions of platelets with collagen, exposed by the subendothelial matrix (167). Although it has been shown that blockade of $\alpha 6 \beta 1$ integrin on platelets could abolish platelettumor cell interaction and tumor metastasis (150), in vivo functions of other types of $\beta 1$ integrins have not been established.

In tumor metastasis models injecting B16F10 melanoma, AT3 breast or MC38 colon cancer cells, we showed that platelet integrin $\alpha 6 \beta 1$ promotes metastasis through the binding to the tumor cell-derived ADAM9 (150). Blockade of integrin $\alpha 6$ functions with $\mathrm{GoH} 3$ antibody could inhibit platelet-tumor cell interaction in vitro and tumor metastasis in vivo (150). Genetic or antibody-mediated blockade of $\alpha 6$ functions in mice did not alter hemostasis or platelet numbers (150). Remarkably, this antibody had no additive effects on tumor metastasis when administered intravenously to platelet $\alpha 6 \beta 1$-deficient mice, at the same time as tumor cells, indicating a predominant role of this platelet integrin during the early steps of tumor metastasis (150). Of note, $\alpha 6 \beta 1$ is also detected in other cells, such as cancer and endothelial cells, and pericytes, transferring pro-tumorigenic effects into the tumor environment (168). Targeting $\alpha 6 \beta 1$ integrin inhibits several routes of integrin-mediated tumor malignancy, therefore blockade of their functions may be a safe anti-cancer strategy. Recent studies by De Archangelis et al. showed that $\alpha 6$ integrin deficiency in mouse intestinal epithelial cells resulted in disruption of hemidesmosome integrity, and mice developed colitis and colorectal carcinoma (169). Integrin $\alpha 6$ deficiency in mice and humans also caused skin and mucous disorders, such as pyloric atresia and epidermolysis bullosa (170). Therefore, determining the in vivo side-effects of $\alpha 6 \beta 1$ blockade is necessary before the therapeutic implication.

Integrin $\alpha \operatorname{IIb} \beta 3$ is the major platelet integrin with a high copy number on the surface, switching from an inactive to an active ligand-binding conformation after agonist stimulation thereby regulating platelet aggregation, thrombosis and hemostasis (171). This transformation allows $\alpha \operatorname{Ilb} \beta 3$ integrin to bind fibrinogen and vWF and those bridge platelets together $(8,171)$. Antagonists of $\alpha \operatorname{IIb} \beta 3$ integrin already used in the treatment of patients with acute coronary diseases (172). Integrillin, a potent $\alpha \mathrm{IIb} \beta 3$ integrin blocker, could effectively inhibit TCIPA and breast cancerassociated bone metastasis (173). Consistently, the genetic ablation of $\beta 3$ integrins in mice inhibited bone metastasis (124).
Of note, deficiency of $\alpha$ Ilb subunit in mice also decreased early steps of lung metastasis, but surprisingly opposite effects were observed at later stages of metastasis (174). The expression of $\alpha \operatorname{IIb} \beta 3$ integrin is not exclusive to platelets, it is also detected on the surface of breast cancer cells (175). In addition, integrillin inhibits $\alpha v \beta 3$ integrin function (176), and this integrin was also detected in cancer and endothelial cells, macrophages, and at low levels on the platelet surface (168), Therefore, blockade of $\beta 3$ integrin function has been suggested as a beneficial therapeutic approach against tumor cells within their environment. However, blockade of $\alpha \operatorname{IIb} \beta 3$ integrin functions in cancer therapy can result in serious side-effects on hemostasis, causing bleeding complications with life-threatening consequences. A possible compromise would be to develop more specific inhibitors that only target the active form of $\alpha \operatorname{IIb} \beta 3$ integrins, reducing the risk of bleeding complications. Recently, several groups have been proposed an alternative strategy to prove this concept, and also partially delete $\alpha \operatorname{IIb} \beta 3$ integrin functions. An antibody-based strategy blocking the thiol-isomerase function of $\alpha \operatorname{IIb} \beta 3$ integrins could inhibit thrombosis without inducing bleeding $(177,178)$. Alternatively, using a single-chain antibody (ScFv) directed against the active form of $\alpha \operatorname{IIb} \beta 3$ integrin, similar antithrombotic effects were observed without any hemostatic complication (179). In line with this, in human cancer xenograft models (breast: MDA-MB-231, SKBr3; fibrosarcoma: HT-1080; Burkitt's lymphoma: Ramos) ScFv antibody effectively targeted the active form of platelet $\alpha \operatorname{IIb} \beta 3$ integrins (180). Recently, an antibody-drug conjugate (ADC) was developed, linking ScFv to a potent chemotherapeutic microtubule inhibitor monomethyl auristatin E (MMAE), against the active form of platelet $\alpha \operatorname{IIb} \beta 3$ integrins and simultaneusly blocking tumor growth and metastasis by MMAE (181). In the tumor microenvironment, MMAE is cleaved from the ADC by cathepsin $\mathrm{B}$, thereby locally releasing the bioactive form of MMAE, killing cancer cells without bleeding complications (181). This promising therapeutic tool would be important to follow in the future using immunocompetent mouse models of cancer.

\section{GPIb-V-IX Complex}

Glycoprotein (GP)Ib-V-IX complex regulates platelet adhesion to the injured sites of a vessel, and platelet aggregation, particularly under the condition of high shear stress (8). This receptor complex is composed of four membrane glycoproteins: GPIb $\alpha$, GPIb $\beta$, GPIX and GPV (8). Using GPIb $\alpha /$ IL4R transgenic mice, replacing the extracellular domains of GPIb $\alpha$ to IL4R, Jain et al. showed that deletion of vWF binding and other binding sites located in these domains of GPIb $\alpha$ could inhibit experimental lung metastasis which was induced by B16F10-melanoma cells (128). Later studies by Erpenbeck et al., showed that treatment with a mixture of GPIb $\alpha$ antibodies (p0p3 and p0p4) directed against vWF binding site on GPIb $\alpha$ could also inhibit tumor metastasis using a similar mouse model of lung metastasis (182). However, p0p3/p0p4 antibodies against GPIb $\alpha$ induced severe thrombocytopenia (182), which probably accounts for this inhibitory effect. Surprisingly, another GPIb $\alpha$ antibody ( $\mathrm{p} 0 \mathrm{p} / \mathrm{B}$ Fab fragment) 
enhanced tumor metastasis in this study (182). Although p0p/B Fab was described to block vWF and thrombin binding to mouse GPIb $\alpha$ and the functional blockade of GPIb $\alpha$ with p0p/B Fab was proved using different platelet functional tests $(183,184)$, the binding epitope on GPIb $\alpha$ has not been mapped at a biochemical level. Taken these results together, it is difficult to conclude at the moment which step of the metastatic cascade is regulated by GPIb $\alpha$. Nevertheless, mice treated with p0p/B Fab displayed prolonged tail-bleeding times (185), indicating a major drawback of such antibody treatment in experimental cancer models.

Recently, the role of GPIb $\alpha$ was further analyzed in experimental (Lewis lung carcinoma) and spontaneous (4T1 breast cancer) lung metastasis models using a YQ3 antibody which specifically inhibits GPIb $\alpha$-vWF interaction (129). The authors showed that platelet-tumor cell and platelet-endothelial cell interactions, and TCIPA were inhibited in vitro and also lung metastasis in vivo (129). Control experiments showed that the Fab fragment of YQ3 antibody did not induce platelet activation or clearance, or any off-target effects when it was injected into the GPIb $\alpha /$ IL4R transgenic mice, indicating that this blocking strategy can avoid thrombocytopenia or bleeding complications in cancer mouse models (129).

GPIb $\alpha$ function was also studied in the disease context of inflammation-related carcinogenesis. Platelet-Kupffer cell interaction involves hyaluronan-CD44 binding and early platelet activation in the liver, which contributes to non-alcoholic steatohepatitis (NASH)-associated liver carcinogenesis (186). Genetic deficiency or blockade of GPIb $\alpha$ function using p0p6 antibody, which was earlier described as GPIb $\alpha$ and GPIX inhibitor (186, 187), suppressed NASH-inducing pathological effects, and this process was independent of the interactions of GPIb $\alpha$ with vWF, P-selectin, or $\alpha M \beta 2$ integrin (186). GPIb $\alpha$ blockade is known to inhibit TPO production in the liver. Theoretically, this may influence consequent platelet production and response to TCIPA in this cancer model (188). Future studies are required to test this hypothesis.

A snake venom-derived antagonist anfibatide and humanized anti-GPIb $\alpha$ monoclonal antibody h6B4-Fab have been also proposed as safe antithrombotic agents in different preclinical and clinical studies (189-191). In the future, it would be important to study their functions also in similar mouse models of cancer as mentioned above.

Besides GPIb $\alpha$ specific antibodies, GPIb $\beta$ blocking antibody RAM.1 has been tested in vivo thrombosis models (192). Although RAM.1 treatment had strong anti-thrombotic effects, bleeding times were not affected in mice, excluding major impact on hemostasis (192). However, the physiological role of GPIb $\beta$ and other subunits of the receptor complex (GPV and GPIX) have not been further studied in mouse models of cancer.

\section{Glycoprotein VI}

Glycoprotein VI (GPVI) is a receptor of ITAM-signaling, which is activated with collagen, laminin and fibrin (193). Activation of this receptor regulates diverse physiological processes in platelets, including adhesion, activation, aggregation and procoagulant activity. Although the role of GPVI function in cancer metastasis has been investigated by injecting Lewis lung carcinoma or B16F10 melanoma cells into mice (194), only limited studies explained the exact molecular mechanisms of how platelet GPVI contributes to this process. A soluble form of GPVI, Revacept has been developed and evaluated in clinical trials of patients with thrombotic diseases to disrupt the interaction of platelet-resident GPVI from collagen thereby inhibiting thrombus formation $(195,196)$. Using galectin-3expressing HT29 cells, Dovizio et al. showed that Revacept had an inhibitory effect on COX-2 and platelet-mediated EMT in vitro (197). Recently, we showed that GPVI supports platelet adhesion on colon and breast cancer cells. We identified galectin3 on the surface of these cancer cells and proposed a model that the collagen-like domain of galectin-3 interacts with GPVI (142). This interaction triggered platelet activation and subsequent extravasation of tumor cells, leading to tumor metastasis (142). Using in vitro and in vivo models, we showed that the blockade of this interaction could prevent platelet-tumor cell interactions and inhibited colon and breast cancer cell-associated lung metastasis in mice (142). The effect of galectin-3 can be shared by other members of the galectin family, such as galectin- 1 and galectin-8. Both of these molecules can induce platelet activation (198) and the release of pro-angiogenic molecules that enhance HUVEC angiogenic responses including proliferation and in vitro tubule-like formation (199).

Besides collagen, GPVI can also bind other ECM components, such as fibrin, linking its function to the coagulation cascade and fibrin-dependent pathomechanisms (200-202). Fibrin-GPVI interactions contribute to thrombus growth $(200,201)$, which can also occur in patients with cancer, leading to thromboembolic events. Therefore, it would be necessary to further investigate the role of GPVI in the context of fibrin-dependent cancer progression and metastasis. Only abrogating fibrin binding to GPVI would be important to evaluate in the future and find the distinct role of fibrin-GPVI interaction in tumor malignancy and cancer-induced coagulopathy. Of note, GPVI also interacts with many ECM components and adhesion molecules, such as fibronectin, vitronectin, adiponectin, MMP13, EMMPRIN and histones $(193,203)$. Therefore, we proposed that GPVI-mediated platelet-tumor cell interactions would be cell type-specific, and it may also depend on the repertoire of various ligands, which are overexpressed in different cancer cells. Furthermore, we also showed that genetic deficiency or antibody-mediated inhibition of GPVI can induce intratumoral hemorrhage, thereby increasing the efficacy of chemotherapeutic drugs within the prostate and mammary tumors (91). Although this has been observed in two distinct cancer models, the treatment of humanized GPVI mouse model with B16F10 skin tumor and blocking human GPVI function with Glenzocimab (ACT017) did not cause tumor bleeding (204). Depending on the cancer types, tumor progression and vascularization seem to be regulated by different oncogenic signaling pathways that modify the hemostatic effects of GPVI. 
GPVI has been considered as a potentially safe antithrombotic target based on the observations that its signaling blockade reduces experimental thrombosis without impairing hemostasis (193). GPVI is exclusively expressed in platelet/ megakaryocyte lineage. Antibody blockade or genetic deficiency of GPVI does not influence platelet production or hemostasis, neither in mice nor in humans (193, 205). Altogether, these results strongly indicate that therapeutic strategies based on selective blockade of GPVI function or its interactions with the indicated ligands in some cancer types may blaze the trail for new anti-cancer therapies, preserving normal hemostasis.

\section{C-Type Lectin-Like Receptor-2}

C-type lectin-like receptor-2 (CLEC-2) has a restricted expression pattern in humans, mainly detected in megakaryocytes, platelets, dendritic cells, and Kupffer cells. Genetic or pharmacological blockade of CLEC-2 in mice does not influence platelet production or hemostasis. Therefore, CLEC-2 would be an attractive target for cancer therapy (33). Recently, targeting CLEC-2 function in cancer was proposed to be effective in decreasing hematogenous cancer metastasis, cancer-associated thrombus formation and thrombo-inflammation (33). Injection of B16F10 melanoma cancer cells into the back skin of CLEC-2depleted mice followed by injection of the 2A2B10 monoclonal antibody inhibited thrombus formation in the tumor vessels without developing intratumoral hemorrhages (206). However, the functional vessel density was significantly increased in CLEC2-depleted mice, improving oxygen and nutrient supply in the tumor environment, indirectly promoting tumor proliferation (206). These interesting pathological aspects of CLEC-2 deficiency opens the question of whether pharmacological blockade of CLEC-2 function could be beneficial in cancer patients.

Interestingly, aberrant O-glycosylation was detected on cancer-origin PDPN. The LpMab-2 antibody recognized this specific site and effectively inhibits PDPN-CLEC-2 interaction only in the cancer microenvironment (207). Therefore, it was proposed that an LpMab-2 antibody would be an excellent tool for selectively targeting PDPN-positive cancer cells, inhibiting cancer-related thrombosis within tumor vessels, without interfering with normal cells that are located in lymphatic vessels (207). Other functional blocking monoclonal antibody (mAb, SZ168) against the extracellular domain of human PDPN also significantly inhibited the growth and pulmonary metastasis of human malignant melanoma (208). Of note, simultaneously blocking both CLEC-2 and GPVI receptor functions may cause severe bleeding complications, as it was demonstrated in CLEC2/GPVI-depleted mice (209).

Platelet aggregation-inducing domains (PLAGs) of PDPN were recently identified, linking its function to CLEC-2. Using antiPLAG-neutralizing antibodies, the function of PLAGs was confirmed in CLEC-2 binding, platelet aggregation, and tumor emboli formation indicating that simultaneous inhibition of PLAGs is efficient to block PDPN-mediated tumor growth and metastasis (210). Besides blocking antibodies, several CLEC-2binding small molecules can interrupt CLEC-2-PDPN interaction.
The water extract of Chinese medicine from leaves of Artemisia argyi could irreversibly block CLEC-2-PDPN interaction in a dose-dependent manner (211). This action may result in the prevention of tumor metastases. Another drug, 5-nitrobenzoate2CP also inhibits PDPN-CLEC2 interaction and consequent TCIPA formation without a risk of bleeding (211). Therefore, it was proposed that inhibition of PDPN-CLEC-2-mediated TCIPA may provide effective therapy against metastasis and thromboembolic complications. The modified form of snake venom toxin rhodocytin was also proposed as a potential tool to target CLEC-2 for both anti-platelet and anti-metastatic therapy $(212,213)$.

Altogether, these results suggest that selective blockade of CLEC-2 function on the platelet surface or disruption of PDPN-CLEC-2 interaction would be effective for anti-cancer therapy. Further studies are required using different experimental cancer models and humanized CLEC-2 mice before clinical application.

\section{CYCLOOXYGENASES}

Upon platelet activation, thromboxane $\mathrm{A}_{2}\left(\mathrm{TxA}_{2}\right)$ secretion enhances platelet aggregation and thrombus formation through its thromboxane-receptor (TP) and also induces diverse paracrine effects on neighboring cells in thrombotic and tumorigenic conditions (214). Aspirin (acetylsalicylic acid) irreversibly inhibits the enzymatic activity of cyclooxygenases (COXs) which are involved in arachidonic acid metabolism, producing $\mathrm{TxA}_{2}$ (172). Aspirin binding covalently modifies COX-1 and COX-2 isoforms through acetylation of serine residues 529 and 516, respectively $(215,216)$. Although platelets constitutively express COX-1, COX-2 expression is dramatically upregulated during inflammatory or tumorigenic conditions. Increased COX-2 expression was detected in many cancer types, such as breast, bladder lung, pancreatic, gastric and lung $(217,218)$.

An inhibitory role of aspirin in cancer development was first reported by Gasic et al. in 1973, who observed metastatic inhibition of MCA6 ascites sarcoma cells in aspirin-treated mice (219). Later, many in vitro and preclinical studies analyzed platelet-dependent effects of aspirin on cancer. Pretreated platelets with aspirin could effectively inhibit cancer cell-induced platelet aggregation (220), but in another study this treatment did not inhibit platelet degranulation, adhesion or micro-aggregate formation (221). These processes are possibly triggered by purinergic signalings which are not inhibited by aspirin in platelets (222).

The effect of aspirin on cancer was also investigated in clinical studies. Kune et al, found a lower incidence of colorectal cancer among subjects using aspirin-containing medication (223). In the APACC trial, patients with early stages of colorectal cancer, colorectal adenomas daily use of lysine acetylsalicylate (160 or $300 \mathrm{mg}$ ) demonstrated a positive effect in adenoma recurrence (224). In another clinical trial, a daily low dose of aspirin (81mg) could slightly decrease the incidence of adenomas in patients compared to the placebo group after one year of treatment (225). 
In a randomized clinical trial, patients with familial adenomatous polyposis were treated with aspirin. Polyps were mainly detected in the epithelium of the large intestine and polyp size was decreased compared to the placebo group (226). In Lynch syndrome, which is a non-polyposis colorectal cancer type, the regular aspirin intake $(600 \mathrm{mg})$ also decreased the cancer incidence (227). Frouws et al. showed that regular use of aspirin $(\leq 100 \mathrm{mg})$ significantly improved patient survival with gastrointestinal cancer, including oesophageal, hepatobiliary and colorectal cancer (228), and aspirin treatment could also reduce the risk of pancreatic cancer (229). Later, Rothwell et al., studied data from five large randomized clinical trials of daily aspirin use ( $\geq 75 \mathrm{mg}$ ), including the United Kingdom Thrombosis Prevention Trial (TPT) (230). These studies showed that regular low-dose aspirin is associated with reduced cancer incidence of colorectal cancer both in women and men, smokers and non-smokers (230). They also demonstrated that daily aspirin intake at low dose reduces the risk of cancer metastasis, which also account for the inhibition of cancer deaths at earlier steps (231). Consistent inhibition was observed in the risk of other cancers, e.g. breast, lung and prostate cancers (230-233).

Taken together, it was a long-standing question, how aspirin treatment influences cancer progression and metastasis, whether these mechanisms are platelet-dependent and/or independent. Hypotheses supporting the role of platelet-dependent mechanisms in cancer were based not only on cellular characteristics of platelets but also pharmacodynamics of aspirin treatment and its effects on COX enzymes. The lifetime of human platelets is only 10 days, platelet turnover is very fast in the human body, therefore patients are regularly treated with aspirin every 24 hours $(234,235) .100 \mathrm{mg}$ /day aspirin intake leads to maximal acetylation of circulating platelets and this could significantly reduce $\mathrm{TxB}_{2}$ levels, metabolite product of $\mathrm{TxA}_{2}$ synthesis $(215,236)$. Aspirin has a short half-life (approximately 20 minutes) in the blood, it is rapidly hydrolyzed to salicylic acid by enzymes located in the blood and liver (237). A low dose of aspirin intake could completely and irreversibly inhibit COX-1 activity in platelets, suggesting that aspirin uptake in platelets is a very fast process. Protein synthesis is limited in platelets compared to nucleated cells, that is due to the lack of nuclei and limited mRNA content received from megakaryocytes. Therefore the inhibitory effect of aspirin is more robust in platelets than other nucleated cells in which acetylated COXs can be easily replaced within few hours with newly synthesized enzymes (215). Although COX-1 activity is completely blocked by aspirin, acetylated COX-2 can still form 15R-hydroxyeicosatetraenoic acid (15R-HETE) from arachidonic acid (238). Furthermore, aspirin can target megakaryocytes in the bone marrow as well, therefore aspirin treatment could inhibit COX-1 function in newborn platelets, released by acetylated megakaryocytes (239). Consistently, in studies by Lucotti et al., transfusion of $\mathrm{COX}-1^{+/+}$platelets resulted in increased number of B16F10 melanoma cellinduced lung metastases in thrombocytopenic mice, compared with using COX $-1^{-/-}$platelets $(164,240)$. This study summarized that aspirin has broad platelet-dependent inhibitory effects on different steps of metastasis, including (i) tumor-induced platelet aggregation, (ii) endothelial cell activation, (iii) tumor cell adhesion to the endothelium, and (iv) recruitment of monocytes/macrophages, and (v) formation of a premetastatic niche (240). Altogether, these results suggest that the antimetastatic effects of aspirin could be mainly due to the inhibition of platelet COX-1 activity.

In an experimental cancer mouse model of human familial adenomatous polyposis, deletion of COX-2 reduces the number of polyps in the intestine, indicating a key role of COX-2 in tumorigenesis (241). Can et al. showed that aspirin intake correlates with a low risk of colorectal cancer in patients with higher expression levels of COX-2 compared to those who had lower levels or absent expression (242). Activated platelets, immune cells and also the tumor microenvironment can release different growth factors, cytokines that also stimulate gene expression of COX-2 in cancer cells. In addition, activated platelets enhance COX-2 expression in stromal cells via the release of IL-1 $\beta$, platelet-derived growth factor (PDGF) and TGF- $\beta$, which lead to tumor progression (243). Moreover, PDGF released from platelets together with GPVI-galectin-3 interactions also triggers COX-2 production, thereby enhancing EMT in HT29 colon cancer cells (197). Altogether, these results suggest that platelets may influence tumorigenesis and cancer progression also through direct effects on COX-2, and aspirin treatment can inhibit COX-2-driven functions in a platelet-dependent manner.

COX-independent mechanisms of aspirin have also been observed. In mouse models of colorectal cancer, aspirin can induce apoptosis via degradation of $\mathrm{I} \kappa \mathrm{B} \alpha$, leading to the nuclear translocation of NF- $\mathrm{Kb}$ (244). Inhibition of $\mathrm{Wnt} / \beta$-catenin and extracellular signal-regulated kinase (ERK)-signaling in aspirintreated cells was also described in different cancer cell types (245-247). However, these effects were often occured at supratherapeutic doses and concentrations of aspirin.

In summary, the majority of studies suggest a positive effect of a low dose of aspirin on cancer incidence, metastases, and cancer-associated mortality. However, long-term aspirin treatment can cause gastrointestinal bleeding complications (248), therefore alternative treatments such as TP receptor blocker or gastrointestinal-safe phosphatidylcholine (PC)associated aspirin (249) have been proposed. The benefit and bleeding risks of aspirin-based therapy can vary depending on many factors, including age, gender, and medical history of patients [reviewed in Dovizio et al. (250)].

Additional studies are needed to confirm whether aspirininhibiting effects are directly associated with platelets or tumor cell or tumor microenvironment. It will be important to further study the effect of aspirin as anti-platelet medication in cancer patients with thrombotic complications. Although aspirin treatment improved adoptive $\mathrm{T}$ cell therapy using preclinical models of melanoma cancer (108) and prevented hepatitis Bassociated hepatocellular carcinoma (251), it would be important to address whether aspirin can be used as a universal adjuvant therapy in patients with cancer. 


\section{PURINERGIC RECEPTOR P2Y 12}

The $\mathrm{P}_{2} \mathrm{Y}_{12}$ receptor is a purinergic Gi-coupled ADP receptor expressed on the platelet surface and known to regulate thrombus stability in vivo (252). Currently used inhibitors of $\mathrm{P}_{2} \mathrm{Y}_{12}$ are either indirectly block the receptor, such as the members of the thienopyridine family (ticlopidine, clopidogrel and prasugrel) or direct inhibitors, such as ticagrelor and cangrelor. The bioactive form of thienopyridine-derived metabolic irreversibly inhibits the binding of ADP to the receptor, leading to decreased platelet activation and aggregation responses, and reducing inside-out activation of platelet $\alpha \operatorname{Irb} \beta 3$ integrins (253). Clopidogrel is widely used in patients with coronary artery, cerebrovascular and peripheral vascular diseases (254). Ticagrelor and cangrelor are reversible antagonists, with similar inhibitory properties (172).

Several cancer studies in mouse models indicated the beneficial effects of these inhibitors. In orthotopic models of pancreatic cancer, clopidogrel inhibited tumor development, metastasis and the extent of cancer-associated thrombosis at a dose of $8 \mathrm{mg} / \mathrm{kg}$, which is $4-8$ fold the chronic dose in patients. This treatment probably induces complete inhibition of ADPinduced platelet aggregation (255). More recently it has been shown that in an orthotopic $4 \mathrm{~T} 1$ breast cancer model, ticagrelor $(10 \mathrm{mg} / \mathrm{kg})$, but not clopidogrel $(10 \mathrm{mg} / \mathrm{kg})$ treatment inhibited lung metastasis and improved the survival rate in mice (256). Ticagrelor treatment was associated with reduced tumor cellplatelet aggregates in the lungs $(256,257)$, thereby decreasing the number of tumor metastases. In ovarian cancer models, deficiency of $\mathrm{P}_{2} \mathrm{Y}_{12}$ receptor in platelets or apyrase treatment inhibited ADP-dependent platelet-tumor cell interaction and consequent primary tumor growth (258). In platelet-mediated tumor metastasis, ADP-induced signaling enhanced the platelet AKT kinase pathway, maintained by apoptosis signal-regulating kinase 1-c-jun N-terminal kinase (ASK1-JNK)/p38-mediated phosphorylation of $\mathrm{P}_{2} \mathrm{Y}_{12}$ receptor, thereby linking ADPinduced signaling to platelet mitogen-activated protein kinase (MAPK) signaling pathways (259).

Genetic deficiency of $\mathrm{P}_{2} \mathrm{Y}_{12}$ has also been shown to inhibit lung colonization by Lewis lung carcinoma and B16F10 cells in mice. Interestingly, this effect was associated with inhibition of VEGFR1+ bone marrow-derived cell clusters, and fibronectin deposition in the lung (160). This result further supported a new anti-cancer strategy. A tumor-homing pentapeptide that targets fibrin-fibronectin complexes in the tumor stroma and the vascular wall is called CREKA, coupled to Ticagrelor (260). This CREKA-Ticagrelor complex effectively inhibited plateletinduced migration of tumor cells, and also prevented tumorplatelet interaction thereby suppressing lung metastasis (260).

In pancreatic adenocarcinoma, platelets can drive gemcitabine resistance. Platelet-released nucleotides (ADP and ATP) were found to be the main causative factor that drives gemcitabine resistance, which is completely blocked by Ticagrelor (261). Isorhapontigenin is a polyphenolic compound found in Chinese herbs and grapes with anti-cancer and anti-inflammatory properties. It can selectively inhibit ADP-induced platelet aggregation and inside-out and outside-in activation of $\alpha \operatorname{IIb} \beta 3$ integrins, and also $\delta$-granule secretion. Isorhapontigenin increased adenosine 3',5'-cyclic monophosphate (cAMP) levels and phosphorylation of vasodilator-stimulated phosphoprotein (VASP). On the other hand, decreased Akt phosphorylation was found, suggesting a potential effect of this drug on cAMP and phosphoinositide 3-kinases (PI3K) signaling pathways that are downstream effectors of $\mathrm{P}_{2} \mathrm{Y}_{12}$ receptor (262). Although clopidogrel enhanced anti-tumor and/or anti-metastatic activity of chemotherapeutic agents such as 5-fluorouracil, cyclophosphamide and mitoxantrone, on the other hand, it reduces the anti-cancer activity of doxorubicin, cisplatin and tamoxifen (263). The molecular mechanisms of such divergent activities have not yet been established, possibly based on the modulation of the tumor vasculature through platelet-released factors. It is also important to note that $\mathrm{P}_{2} \mathrm{Y}_{12}$ receptor is expressed in cells other than platelets (264), such as osteoclasts (265). Indeed, bone loss (osteolysis) associated with tumor growth in mice was effectively treated with clopidogrel (265).

Although inhibition of $\mathrm{P}_{2} \mathrm{Y}_{12}$ has beneficial effects in mouse models of cancer, the results from randomized trials are conflicting. TRITON-TIMI 38 trial of prasugrel in comparison to clopidogrel on top of aspirin during 6-15 months indicated on accelerated tumor growth and a higher risk of cancer death in the prasugrel group, in patients with breast, colorectal and prostate cancers (266). Interestingly, this effect was not observed in patients with non-melanoma type of skin cancers and brain tumors (266). In contrast, in another trial (TRILOGY), no difference has been observed in the occurrence of cancer between the clopidogrel and prasugrel group (267). In DAPT and PEGASUS-TIMI 54 trials, long-term treatment with clopidogrel and ticagrelor also showed a significant increase in cancer-related deaths $(268,269)$. In a retrospective study on acute coronary syndrome patients with a median follow-up of 46 months, ticagrelor treatment had lower cancer risk than clopidogrel without any difference between clopidogrel and prasugrel (270). Although these studies have been conducted in large cohorts, it is difficult to conclude any evidence of the association between the effects of $\mathrm{P}_{2} \mathrm{Y}_{12}$ inhibitors and cancer risk and related mortality. Earlier, it was hypothesized in some cases, that platelet-tumor cell trapping in the microvasculature has anti-metastatic effects, and inhibition of platelet function using these drugs may impair the barrier function of platelets (271).

\section{Thrombin and Thrombin Receptors}

Thrombin receptors belong to a PAR family of four transmembrane GPCRs that are activated by thrombin, and trypsin-like protease-mediated cleavage of their $\mathrm{N}$ terminal exodomain $(272,273)$. PARs are expressed in platelets, neutrophils, monocytes/macrophages, endothelial cells and fibroblasts. The human platelets are mainly activated by thrombin through PAR1 and PAR4 isoforms, while mouse platelets do not express PAR1, they are activated by PAR3 and PAR4. Thrombin receptors are an attractive target for the treatment of platelet-related diseases (274). Targeting platelet PAR1 function could effectively inhibit thrombin-induced aggregation. PAR1 blocker Vorapaxar can reduce thrombotic 
events in patients with myocardial infarction and stroke, but moderate or severe bleeding complications were observed (275). Parmodulin targets the cytosolic part of PAR1 in reversible mode, thereby inhibiting signalings through Goq, but not Go12/13. Parmodulin ML-161 had anti-thrombotic and antiinflammatory effects in mice with a lower bleeding tendency (276). Pepducin is a cell-penetrating lipidated fragment of the cytosolic part of GPCR to modulate the action of this receptor in targeted cell-signaling pathways, including different PARs. PAR1 specific Pepducin PZ-128 was proposed as an effective antimetastatic and anti-angiogenic inhibitor in mouse models of breast, lung and ovarian cancers (277). PZ-128 has been already tested in patients with coronary diseases and resulted in decreased bleeding tendency compared to Vorapaxar (278). Interestingly, PAR1 was detected in different cancer cells, and it was cleaved by MMP1 and 13 (279). Therefore, it was proposed that targeting PAR1 function during cancer progression and metastasis would simultaneously inhibit both platelet and tumor cell functions. The clinical applicability of Parmodulin and Pepducin in cancer therapy would be important to further study in different in vivo experimental models of cancer.

Heparin prevents the formation of thrombin and inhibits its activity. Heparin, unfractionated heparin (UFH), low-molecularweight heparin (LMWH) and heparin derivatives are used in the treatment of VTE and can suppress cancer cell survival (280). Heparin inhibits angiogenesis, tumor cell proliferation, adhesion, migration and invasion through the inhibition of heparanase, $\mathrm{P}$ and L-selectin. Furthermore, heparin treatment inhibits tumor cell-induced endothelial tube formation and CXCL12/CXCR4 signaling pathways (280). Tinzaparin is an LMWH, generated by the enzymatic degradation of porcine unfractionated heparin (UFH). Sulfated non-anti-coagulant heparin (S-NACH) is also an LMWH (281). Both LMWH effectively inhibits P-selectinmediated cell adhesion and cancer metastasis. Modified heparin with low anti-coagulant activity decreases A375 melanoma cell adhesion to platelets through inhibition of inside-out activation of $\alpha \operatorname{IIb} \beta 3$ integrins (282). Heparin can also disrupt the interaction of monocyte and tumor cell-derived $\alpha 4 \beta 1$ with endothelial vascular cell adhesion molecule 1 (VCAM1) (283). Although the anti-cancer effects of heparin and its derivatives have been highlighted in the literature, more preclinical and clinical studies are necessary to evaluate the potential off-target effects in heparin-based platelet-cancer therapies to avoid bleeding complications.

\section{P SELECTIN}

P-selectin mediates interactions of platelets with tumor cells and vasculature during tumor growth and metastasis, indicating that blockade of P-selectin exposure on the platelet surface would be a potential target for anti-cancer therapy. Rivipansel inhibits many selectins in the body, including $\mathrm{P}, \mathrm{L}$ and E-selectins, and also decreases the recruitment of plasma cells to the bone marrow of multiple myeloma (284). Rivipansel treatment was tested in patients with vaso-occlusive sickle cell anemia and this treatment did not reach the necessary efficacy points (285).
Recently, Crizanlizumab, a selective blocking antibody of Pselectin was tested in the same disease context with a lower incidence of adverse effects (286). Therefore, it would be important to test Crizanlizumab in different cancer mouse models in the future.

\section{Liquid Biopsies}

Blood-based liquid biopsies are non-invasive biomarkers, which are becoming powerful diagnostic and prognostic tools to screen cancer patients (287). To evaluate tumor landscape, circulating tumor cells (CTCs) are the most commonly used liquid biopsies (287). During their transit in the bloodstream, CTCs interact with platelets and immune cells. Platelets can ingest and sequester CTC-specific proteins, mRNA and also tumorderived pro-tumorigenic and angiogenic factors, leading to the tumor-specific modifications of platelet proteome and transcriptome. In line with this, platelets isolated from patients with glioma and prostate cancer were enriched in cancerassociated RNA biomarkers EGFRvIII and PCA (288). Best et al, detected more than 5000 differentially expressed or mutated mRNAs between healthy donors and cancer patients, including expression of MET, HER2 and mutations in KRAS, EGFR and PIK3CA (289). These datasets were effective to distinguish patients with metastatic tumors. During tumor progression, platelet transcriptome seems to dynamically change in a timedependent manner. Therefore, it was proposed that the platelet mRNA profile allowed to accurately distinguish and predict tumor progression (290). Analyzing platelets as a reservoir of liquid biopsies would provide valuable tools for cancer diagnostics. On another hand recent studies by Dunbar et al., reported that regardless of cancer type, the mutations in genes, such as STK11, KRAS, CTNNB1, KEAP, CDKN2B and MET can predict the high incidence of cancer-associated thrombosis for one year before diagnosis $(291,292)$. Interestingly other genes, such as SETD2, IDH1 are not predictive and displayed a negative association $(291,292)$.

Soluble P-selectin and coagulation factors circulate at high levels in patients with solid cancers, predicting the cancer status and VTE complications $(24,293,294)$. High plasma levels of vWF, fibrinogen and D-dimers were associated with poor prognosis of breast, colon, gastric, rectal, non-small cell lung cancer, ovarian and pancreatic cancers (295-298). Other studies observed elevated levels of TF-positive microparticles in plasma samples of patients with pancreatic, colon, breast, ovarian and non-small cell lung cancer (299). Although systematic testing of cancer patients for these pro-coagulant factors may help to identify patients at increased risk for VTE, genomic profiling of oncogenic mutations can be also useful to predict thromboembolic risks in patients with different solid cancer types. It would be important to further evaluate whether increased VTE observed in cancer patients is due to the oncogenic mutations which dysregulate the hemostatic genes in cancer cells, leading to enhanced TCIPA, thrombosis and blood clotting.

Plasma levels of soluble GPVI (sGPVI) reflect platelet activation in thrombo-inflammatory diseases, such as stroke, disseminated intravascular coagulopathy, arthritis and sepsis (300-302). GPVI 
can support thrombus stabilization through the interaction with fibrin and fibrinogen $(200,201,303)$. Elevated levels of sGPVI in patients with sepsis were due to the GPVI shedding, which was induced by fibrin activation of this receptor (304). Recently, we found increased levels of sGPVI in plasma samples of patients with breast or colorectal cancer (142). In small cohorts of patients with colorectal cancer, sGPVI levels were positively correlated with cancer stage (142). To establish the role of sGPVI as a diagnostic/prognostic marker, future studies are needed to validate these results in a larger cohort involving other solid tumor types. Although the pro-thrombotic environment of many cancers is rich in fibrin (305), future studies are required to evaluate whether levels of sGPVI can be also a diagnostic tool to predict thrombosis and correlated to the cancer stage. GPVI would also represent a prognostic marker in pancreatic adenocarcinoma since elevated levels of GPVI were detected in microparticles isolated from patient blood (306). Further studies are required to define whether some of the aboveindicated platelet-derived molecules can be universal diagnostic/ prognostic markers for cancers or only specific of a particular cancer type.

\section{OTHER ALTERNATIVE TARGETING STRATEGIES}

It has been proposed that platelets can influence tumor growth and progression by enhancing tumor cell proliferation (307). However, the role of platelets on cancer cell proliferation remains controversial. Experimental findings were strongly dependent on the cancer cell types and in vitro cell culture systems. Initial studies by Ibele et al. showed that platelets have an important role in malignant tumors because leukocytes enhance the killing capacity against cancer cells in the presence of platelets (308). Another study showed that resting and thrombin-stimulated platelets exert the cytotoxic effect on K562 chronic myelogenous leukemia cells (309). Although this cytotoxic effect was abolished by esterase inhibitors in resting but not in thrombin-activated platelets (309). This phenomenon can be explained that platelets can express many immune defense factors, such as TNF, tumor necrosis factor-related apoptosisinducing ligand (TRAIL), CD154 and Fas-L, and exposed on the platelet surface or released into the medium. The binding of Fas$\mathrm{L}$ to Fas receptor (Fas-R) activates the caspase-mediated apoptotic pathway in cancer cells that express Fas-R (310).

Anoikis is a form of programmed cell death that occurs when cancer cells detached from the surrounding ECM, thereby modulating cell spreading and invasiveness (311). Interestingly, platelets induce resistance of cancer cells to anoikis (312). Platelets also enhance RhoA-MYPT1-PP1-mediated YAP1 dephosphorylation in cancer cells, thereby inducing a prosurvival gene expression signature and inhibiting apoptosis (312). Altogether, these studies suggest that platelets contain an arsenal of bioactive factors, manipulating the apoptotic crosstalks between platelets and tumor cells. In addition, platelets can induce cell proliferation of hepatocellular carcinoma by activating MAPK signaling and decreasing apoptotic mediators (313). Platelet releasate also enhances cell proliferation of human and mouse ovarian cancer, and this process is maintained by the interaction between platelet-released TGF- $\beta$ and tumor-resident TGF- $\beta$ receptor (314). In orthotopic xenograft, syngeneic and genetic models of ovarian and lung cancer, other platelet-derived molecules, platelet focal adhesion kinase (FAK) and PF4 enhanced platelet infiltration and tumor growth $(315,316)$.

Genetically modified platelets expressing TRAIL on the cell surface could eliminate cancer cells in vitro and significantly reduce the number of metastases in a mouse model of prostate cancer (317). Hu et al. used a platelet membrane-coated nanovehicles (PM-NV) for sequential and site-specific delivery of two anti-cancer therapeutics (TRAIL and doxorubicin) (318). PM-NV can efficiently deliver TRAIL toward cancel cell membrane to activate the extrinsic signaling pathway of apoptosis (318). Papa et al. developed detergent-extracted human-modified platelets (platelet decoys) that retained platelet binding functions but were incapable of functional activation and aggregation (319). Their results suggest that platelet decoys could represent an effective strategy for obtaining anti-metastatic and even anti-thrombotic effects (319). In vivo rabbit model, pretreatment with platelet decoys inhibited arterial injury-induced thromboembolism and also interfered with platelet-mediated human breast cancer cell aggregation, and decreased cancer cell arrest and extravasation in a microfluidic human microvasculature on a chip (319). In a mouse model of metastasis, simultaneous injection of the platelet decoys with tumor cells inhibited metastatic tumor growth (319).

In many studies, platelets have been proposed as a drug carrier, since platelets can easily uptake and store bioactive molecules in their secretory granules. Doxorubicin was loaded in platelets for the treatment of lymphoma. Doxorubicin-treated platelets facilitated intracellular drug accumulation through TCIPA and also could release doxorubicin into the medium in a pH-controlled manner (320). This study suggested that doxorubicin-loaded platelets could reduce the adverse effects of extracellular doxorubicin, and enhance the therapeutic efficacy in the targeted organ (320). As we mentioned above, an antibodydrug conjugate $(\mathrm{ADC})$ with the combination of drug activation and release resulted in tumor cytotoxicity in a mouse xenograft model of triple-negative breast cancer (MDA-MB-231 cells) without any discernible toxic effects on other cell types (181). Loading platelets with ADC-conjugated drugs carrying to the tumor microenvironment would be a novel therapeutic approach for the treatment of a broad range of solid tumors (181).

\section{Platelets and Chemotherapy Resistance}

Tumor chemotherapy resistance occurs when a tumor that has been responding to therapy suddenly begins to grow, and cancer cells could escape from the toxic effects of chemotherapeutic agents. This represents one of the major problems in patients with chemotherapy resistance (311) because of the higher risk to develop thromboembolic disorders than those without chemotherapy $(321,322)$. Clinical studies showed the correlation between platelet count and tumor chemotherapy resistance. In vitro studies demonstrated the contribution of increased 
platelet count to tumor chemotherapy resistance, when paclitaxel and 5-fluorouracil have been used for the killing of colon and ovarian cancer cells (323). In mouse models of breast and prostate carcinoma, low platelet count could increase the sensitivity to doxorubicin and paclitaxel $(91,92)$. Inhibition of GPVI function resulted in intratumoral hemorrhages, and this could enhance the access of the chemotherapeutic agents into the growing breast and prostate tumors (91). Platelets also contribute to the relapse of orthotopic ovarian tumors in mice after cessation of anti-angiogenic therapy with bevacizumab or pazopanib (315). Platelet FAK function is important in this process because FAK-deficient platelets completely prevented the rebound in tumor growth (315). In line with this, combined therapy with a FAK inhibitor and pazopanib/bevacizumab could inhibit the negative effects following the withdrawal of antiangiogenic therapy (315). Altogether, it was proposed that FAK may be a unique target when anti-angiogenic agents are withdrawn, and dual inhibition of FAK and VEGF may have a therapeutic implication for ovarian cancer management (315).

Several mechanisms have been proposed that platelet releasate may also influence tumor chemotherapy resistance, thereby antagonizing the cytotoxic effect of some drugs, such as paclitaxel and 5-fluorouracil: (i) growth factors and cytokines released from activated platelets counter the anti-proliferative effects of chemotherapeutic agents by shifting the balance between anti-apoptotic and pro-apoptotic genes, (ii) platelets upregulate the regulators of cell progression thereby inducing the blocking of cell cycle arrest caused by the anti-cancer agents, (iii) platelets enhance the phosphorylation of DNA repair proteins, Chk1, BRCA1 and Mre11. Interestingly, platelets inhibited cytotoxic effects of chemotherapeutic agents sorafenib and regorafenib in hepatocellular carcinoma by increasing MAPK signaling (307). Proposed molecular mechanisms are multiple, how they can be applicable at clinical levels, warrant still many investigations.

\section{REFERENCES}

1. Chaffer CL, Weinberg RA. A Perspective on Cancer Cell Metastasis. Science (2011) 331(6024):1559-64. doi: 10.1126/science.1203543

2. Seyfried TN, Huysentruyt LC. On the Origin of Cancer Metastasis. Crit Rev Oncog (2013) 18(1-2):43-73. doi: 10.1615/CritRevOncog.v18.i1-2.40

3. Hanahan D, Weinberg RA. Hallmarks of Cancer: The Next Generation. Cell (2011) 144(5):646-74. doi: 10.1016/j.cell.2011.02.013

4. Hanahan D, Weinberg RA. The Hallmarks of Cancer. Cell (2000) 100(1):5770. doi: 10.1016/S0092-8674(00)81683-9

5. Duan Q, Zhang H, Zheng J, Zhang L. Turning Cold Into Hot: Firing Up the Tumor Microenvironment. Trends Cancer (2020) 6(7):605-18. doi: 10.1016/ j.trecan.2020.02.022

6. Gay LJ, Felding-Habermann B. Contribution of Platelets to Tumour Metastasis. Nat Rev Cancer (2011) 11(2):123-34. doi: 10.1038/nrc3004

7. Brass LF, Diamond SL, Stalker TJ. Platelets and Hemostasis: A New Perspective on an Old Subject. Blood Adv (2016) 1(1):5-9. doi: 10.1182/bloodadvances.2016000059

8. Xu XR, Carrim N, Neves MA, McKeown T, Stratton TW, Coelho RM, et al. Platelets and Platelet Adhesion Molecules: Novel Mechanisms of Thrombosis and Anti-Thrombotic Therapies. Thromb J (2016) 14(Suppl 1):29. doi: 10.1186/s12959-016-0100-6

\section{CONCLUSION}

Platelets can build dynamic interactions with all other cell types in the circulation and trigger many activatory signaling pathways, thereby directly or indirectly influencing the function of tumor cells and tumor stroma. Platelets display predominantly pro-tumorigenic functions in different cancer types. Experimental and preclinical studies using knock-out animal models and a wide range of pharmacological tools provided encouraging results to consider platelets as potential targets in anti-cancer therapies. However, the clinical evidence of the beneficial effects of anti-platelet therapies in cancer is still missing. Design of optimal anti-cancer therapy in patients with active tumor malignancy is a highly challenging task. Therefore, future studies adding anti-platelet drugs into the conventional anti-cancer therapies must carefully examine many factors, including cancer type, degree of malignancy, sex, age, bleeding profile, and other risk factors, before that these drugs are applied to the patients. More experimental and preclinical studies are required to address the therapeutic value of anti-platelet strategies in solid cancers.

\section{AUTHOR CONTRIBUTIONS}

$\mathrm{AB}$ and EM-B wrote the manuscript. H-JA and TG critically reviewed the manuscript. All authors contributed to the article and approved the submitted version.

\section{FUNDING}

This work was supported by the Bayersiches Landesamt für Gesundheit und Lebensmittelsicherheit (project number 15-25) and Deutsche Forschungsgemeinschaft, CRC TRR152/P15.

9. Mammadova-Bach E, Nagy M, Heemskerk JWM, Nieswandt B, Braun A. Store-Operated Calcium Entry in Thrombosis and Thrombo-Inflammation. Cell Calcium (2019) 77:39-48. doi: 10.1016/j.ceca.2018.11.005

10. Scharf RE. Platelet Signaling in Primary Haemostasis and Arterial Thrombus Formation: Part 2. Hamostaseologie (2018) 38(4):211-22. doi: 10.1055/s0038-1675149

11. Scharf RE. Platelet Signaling in Primary Haemostasis and Arterial Thrombus Formation: Part 1. Hamostaseologie (2018) 38(4):203-10. doi: 10.1055/s0038-1675144

12. Fernandes CJ, Morinaga LTK, Alves JLJr., Castro MA, Calderaro D, Jardim CVP, et al. Cancer-Associated Thrombosis: The When, How and Why. Eur Respir Rev (2019) 28(151):180119. doi: 10.1183/16000617.0119-2018

13. Mukai M, Oka T. Mechanism and Management of Cancer-Associated Thrombosis. J Cardiol (2018) 72(2):89-93. doi: 10.1016/j.jjcc.2018.02.011

14. Mammadova-Bach E, Mangin P, Lanza F, Gachet C. Platelets in Cancer. From Basic Research to Therapeutic Implications. Hamostaseologie (2015) 35(4):325-36. doi: 10.5482/hamo-14-11-0065

15. Abdel-Razeq H, Mansour A, Saadeh SS, Abu-Nasser M, Makoseh M, Salam $\mathrm{M}$, et al. The Application of Current Proposed Venous Thromboembolism Risk Assessment Model for Ambulatory Patients With Cancer. Clin Appl Thromb Hemost (2018) 24(3):429-33. doi: 10.1177/1076029617692880 
16. Patell R, Rybicki L, McCrae KR, Khorana AA. Predicting Risk of Venous Thromboembolism in Hospitalized Cancer Patients: Utility of a Risk Assessment Tool. Am J Hematol (2017) 92(6):501-7. doi: 10.1002/ajh.24700

17. Munoz Martin AJ, Ortega I, Font C, Pachon V, Castellon V, Martinez-Marin V, et al. Multivariable Clinical-Genetic Risk Model for Predicting Venous Thromboembolic Events in Patients With Cancer. Br J Cancer (2018) 118 (8):1056-61. doi: 10.1038/s41416-018-0027-8

18. Blom JW, Doggen CJ, Osanto S, Rosendaal FR. Malignancies, Prothrombotic Mutations, and the Risk of Venous Thrombosis. JAMA (2005) 293(6):71522. doi: 10.1001/jama.293.6.715

19. Stone RL, Nick AM, McNeish IA, Balkwill F, Han HD, Bottsford-Miller J, et al. Paraneoplastic Thrombocytosis in Ovarian Cancer. $N$ Engl J Med (2012) 366(7):610-8. doi: 10.1056/NEJMoa1110352

20. Cerutti A, Custodi P, Duranti M, Noris P, Balduini CL. Thrombopoietin Levels in Patients With Primary and Reactive Thrombocytosis. $\mathrm{Br} J$ Haematol (1997) 99(2):281-4. doi: 10.1046/j.1365-2141.1997.3823196.x

21. Kaser A, Brandacher G, Steurer W, Kaser S, Offner FA, Zoller H, et al. Interleukin-6 Stimulates Thrombopoiesis Through Thrombopoietin: Role in Inflammatory Thrombocytosis. Blood (2001) 98(9):2720-5. doi: 10.1182/ blood.V98.9.2720

22. Josa V, Ferenczi S, Szalai R, Fuder E, Kuti D, Horvath K, et al. Thrombocytosis and Effects of IL-6 Knock-Out in a Colitis-Associated Cancer Model. Int J Mol Sci (2020) 21(17):6218. doi: 10.3390/ijms21176218

23. Besbes S, Shah S, Al-Dybiat I, Mirshahi S, Helfer H, Najah H, et al. Thrombopoietin Secretion by Human Ovarian Cancer Cells. Int J Cell Biol (2017) 1873834. doi: 10.1155/2017/1873834

24. Riedl J, Hell L, Kaider A, Koder S, Marosi C, Zielinski C, et al. Association of Platelet Activation Markers With Cancer-Associated Venous Thromboembolism. Platelets (2016) 27(1):80-5. doi: 10.3109/09537104.2015.1041901

25. Ludwig RJ, Schon MP, Boehncke WH. P-Selectin: A Common Therapeutic Target for Cardiovascular Disorders, Inflammation and Tumour Metastasis. Expert Opin Ther Targets (2007) 11(8):1103-17. doi: 10.1517/14728222.11.8.1103

26. Ay C, Pabinger I. Predictive Potential of Haemostatic Biomarkers for Venous Thromboembolism in Cancer Patients. Thromb Res (2012) 129 Suppl 1:S6-9. doi: 10.1016/S0049-3848(12)70008-7

27. Rank A, Liebhardt S, Zwirner J, Burges A, Nieuwland R, Toth B. Circulating Microparticles in Patients With Benign and Malignant Ovarian Tumors. Anticancer Res (2012) 32(5):2009-14.

28. Reddel CJ, Tan CW, Chen VM. Thrombin Generation and Cancer: Contributors and Consequences. Cancers (Basel) (2019) 11(1):100. doi: $10.3390 /$ cancers 11010100

29. Jurasz P, Alonso-Escolano D, Radomski MW. Platelet-Cancer Interactions: Mechanisms and Pharmacology of Tumour Cell-Induced Platelet Aggregation. Br J Pharmacol (2004) 143(7):819-26. doi: 10.1038/ sj.bjp. 0706013

30. Suzuki-Inoue K. Roles of the CLEC-2-Podoplanin Interaction in Tumor Progression. Platelets (2018) 29(8):786-92. doi: 10.1080/09537104. 2018.1478401

31. Lee HY, Yu NY, Lee SH, Tsai HJ, Wu CC, Cheng JC, et al. Podoplanin Promotes Cancer-Associated Thrombosis and Contributes to the Unfavorable Overall Survival in an Ectopic Xenograft Mouse Model of Oral Cancer. BioMed J (2020) 43(2):146-62. doi: 10.1016/j.bj.2019.07.001

32. Riedl J, Preusser M, Nazari PM, Posch F, Panzer S, Marosi C, et al. Podoplanin Expression in Primary Brain Tumors Induces Platelet Aggregation and Increases Risk of Venous Thromboembolism. Blood (2017) 129(13):1831-9. doi: 10.1182/blood-2016-06-720714

33. Suzuki-Inoue K. Platelets and Cancer-Associated Thrombosis: Focusing on the Platelet Activation Receptor CLEC-2 and Podoplanin. Blood (2019) 134 (22):1912-8. doi: 10.1182/blood.2019001388

34. Kasthuri RS, Taubman MB, Mackman N. Role of Tissue Factor in Cancer. J Clin Oncol (2009) 27(29):4834-8. doi: 10.1200/JCO.2009.22.6324

35. Zara M, Canobbio I, Visconte C, Canino J, Torti M, Guidetti GF. Molecular Mechanisms of Platelet Activation and Aggregation Induced by Breast Cancer Cells. Cell Signal (2018) 48:45-53. doi: 10.1016/j.cellsig.2018.04.008

36. Yang C, Ma R, Jiang T, Cao M, Zhao L, Bi Y, et al. Contributions of Phosphatidylserine-Positive Platelets and Leukocytes and Microparticles to Hypercoagulable State in Gastric Cancer Patients. Tumour Biol (2016) 37 (6):7881-91. doi: 10.1007/s13277-015-4667-5
37. Aghourian MN, Lemarie CA, Bertin FR, Blostein MD. Prostaglandin E Synthase Is Upregulated by Gas6 During Cancer-Induced Venous Thrombosis. Blood (2016) 127(6):769-77. doi: 10.1182/blood-2015-02628867

38. Meikle CK, Meisler AJ, Bird CM, Jeffries JA, Azeem N, Garg P, et al. PlateletT Cell Aggregates in Lung Cancer Patients: Implications for Thrombosis. PloS One (2020) 15(8):e0236966. doi: 10.1371/journal.pone.0236966

39. Harsfalvi J, Molnar Z, Csanyi MC, Domjan I, Flasko T, Kaposi A, et al. LongLasting Prothrombotic State Implied by Changes of Plasma Von Willebrand Factor Parameters After Radical Prostatectomy for Prostate Malignancy. Urol Oncol (2020) 38(4):191-7. doi: 10.1016/j.urolonc.2019.10.007

40. Rudzinski JK, Govindasamy NP, Lewis JD, Jurasz P. The Role of the Androgen Receptor in Prostate Cancer-Induced Platelet Aggregation and Platelet-Induced Invasion. J Thromb Haemost (2020) 18(11):2976-86. doi: $10.1111 /$ jth. 15020

41. Mitrugno A, Williams D, Kerrigan SW, Moran N. A Novel and Essential Role for FcgammaRIIa in Cancer Cell-Induced Platelet Activation. Blood (2014) 123(2):249-60. doi: 10.1182/blood-2013-03-492447

42. Miao S, Shu D, Zhu Y, Lu M, Zhang Q, Pei Y, et al. Cancer Cell-Derived Immunoglobulin G Activates Platelets by Binding to Platelet FcgammaRIIa. Cell Death Dis (2019) 10(2):87. doi: 10.1038/s41419-019-1367-x

43. Sorvillo N, Cherpokova D, Martinod K, Wagner DD. Extracellular DNA NET-Works With Dire Consequences for Health. Circ Res (2019) 125 (4):470-88. doi: 10.1161/CIRCRESAHA.119.314581

44. Mauracher LM, Posch F, Martinod K, Grilz E, Daullary T, Hell L, et al. Citrullinated Histone H3, A Biomarker of Neutrophil Extracellular Trap Formation, Predicts the Risk of Venous Thromboembolism in Cancer Patients. J Thromb Haemost (2018) 16(3):508-18. doi: 10.1111/jth.13951

45. Hisada Y, Mackman N. Update From the Laboratory: Mechanistic Studies of Pathways of Cancer-Associated Venous Thrombosis Using Mouse Models. Hematol Am Soc Hematol Educ Program (2019) 2019(1):182-6. doi: 10.1182/hematology.2019000025

46. Wculek SK, Malanchi I. Neutrophils Support Lung Colonization of Metastasis-Initiating Breast Cancer Cells. Nature (2015) 528(7582):413-7. doi: $10.1038 /$ nature 16140

47. Coffelt SB, Kersten K, Doornebal CW, Weiden J, Vrijland K, Hau CS, et al. IL-17-Producing Gammadelta T Cells and Neutrophils Conspire to Promote Breast Cancer Metastasis. Nature (2015) 522(7556):345-8. doi: 10.1038/ nature 14282

48. Mammadova-Bach E, Gil-Pulido J, Jorgacevic I, Beck S, Remer K, Braun A, et al. Transforming Growth Factor $\beta$ Released by Platelets Primes Macrophage Activation and Extracellular Trap Formation, Thereby Influencing Breast Cancer Growth in Mice. In: ISTH Academy, 07/10/19; 274035; OC 79.4 Platelet Function \& Interactions (2019).

49. Shi C, Kim T, Steiger S, Mulay SR, Klinkhammer BM, Bauerle T, et al. Crystal Clots as Therapeutic Target in Cholesterol Crystal Embolism. Circ Res (2020) 126(8):e37-52. doi: 10.1161/CIRCRESAHA.119.315625

50. Shi C, Yang L, Braun A, Anders HJ. Extracellular DNA-A Danger Signal Triggering Immunothrombosis. Front Immunol (2020) 11:568513. doi: $10.3389 /$ fimmu.2020.568513

51. Okubo K, Kurosawa M, Kamiya M, Urano Y, Suzuki A, Yamamoto K, et al. Macrophage Extracellular Trap Formation Promoted by Platelet Activation Is a Key Mediator of Rhabdomyolysis-Induced Acute Kidney Injury. Nat Med (2018) 24(2):232-8. doi: 10.1038/nm.4462

52. Gomez RM, Lopez Ortiz AO, Schattner M. Platelets and Extracellular Traps in Infections. Platelets (2021) 32(3):305-13. doi: 10.1080/09537104. 2020.1718631

53. Wen F, Shen A, Choi A, Gerner EW, Shi J. Extracellular DNA in Pancreatic Cancer Promotes Cell Invasion and Metastasis. Cancer Res (2013) 73 (14):4256-66. doi: 10.1158/0008-5472.CAN-12-3287

54. Eelen G, Treps L, Li X, Carmeliet P. Basic and Therapeutic Aspects of Angiogenesis Updated. Circ Res (2020) 127(2):310-29. doi: 10.1161/ CIRCRESAHA.120.316851

55. Klement GL, Yip TT, Cassiola F, Kikuchi L, Cervi D, Podust V, et al. Platelets Actively Sequester Angiogenesis Regulators. Blood (2009) 113(12):2835-42. doi: 10.1182/blood-2008-06-159541

56. Battinelli EM, Markens BA, Italiano JEJr. Release of Angiogenesis Regulatory Proteins From Platelet Alpha Granules: Modulation of Physiologic and 
Pathologic Angiogenesis. Blood (2011) 118(5):1359-69. doi: 10.1182/blood2011-02-334524

57. Wang ZH, Zhu ZT, Xiao XY, Sun J. Correlation of Serum Levels of Endostatin With Tumor Stage in Gastric Cancer: A Systematic Review and Meta-Analysis. BioMed Res Int (2015) 2015:623939. doi: 10.1155/2015/ 623939

58. Drenberg CD, Saunders BO, Wilbanks GD, Chen R, Nicosia RF, Kruk PA, et al. Urinary Angiostatin Levels Are Elevated in Patients With Epithelial Ovarian Cancer. Gynecol Oncol (2010) 117(1):117-24. doi: 10.1016/j.ygyno.2009.12.011

59. Cymbaluk-Ploska A, Chudecka-Glaz A, Pius-Sadowska E, Machalinski B, Menkiszak J. Thrombospondin-I Concentrations Behavior in Plasma of Patients With Ovarian Cancer. Cancer Biomark (2017) 20(1):31-9. doi: $10.3233 / \mathrm{CBM}-161546$

60. Jonnalagadda D, Izu LT, Whiteheart SW. Platelet Secretion Is Kinetically Heterogeneous in an Agonist-Responsive Manner. Blood (2012) 120 (26):5209-16. doi: 10.1182/blood-2012-07-445080

61. Kamykowski J, Carlton P, Sehgal S, Storrie B. Quantitative Immunofluorescence Mapping Reveals Little Functional Coclustering of Proteins Within Platelet Alpha-Granules. Blood (2011) 118(5):1370-3. doi: 10.1182/blood-2011-01-330910

62. van Holten TC, Bleijerveld OB, Wijten P, de Groot PG, Heck AJ, Barendrecht AD, et al. Quantitative Proteomics Analysis Reveals Similar Release Profiles Following Specific PAR-1 or PAR-4 Stimulation of Platelets. Cardiovasc Res (2014) 103(1):140-6. doi: 10.1093/cvr/cvu113

63. Etulain J, Mena HA, Negrotto S, Schattner M. Stimulation of PAR-1 or PAR4 Promotes Similar Pattern of VEGF and Endostatin Release and ProAngiogenic Responses Mediated by Human Platelets. Platelets (2015) 26 (8):799-804. doi: 10.3109/09537104.2015.1051953

64. Miao X, Zhang W, Huang Z, Li N. Unaltered Angiogenesis-Regulating Activities of Platelets in Mild Type 2 Diabetes Mellitus Despite a Marked Platelet Hyperreactivity. PloS One (2016) 11(9):e0162405. doi: 10.1371/ journal.pone. 0162405

65. Bergstrand J, Xu L, Miao X, Li N, Oktem O, Franzen B, et al. SuperResolution Microscopy can Identify Specific Protein Distribution Patterns in Platelets Incubated With Cancer Cells. Nanoscale (2019) 11(20):10023-33. doi: 10.1039/C9NR01967G

66. Montague SJ, Lim YJ, Lee WM, Gardiner EE. Imaging Platelet Processes and Function-Current and Emerging Approaches for Imaging In Vitro and In Vivo. Front Immunol (2020) 11:78. doi: 10.3389/fimmu.2020.00078

67. Salgado R, Junius S, Benoy I, Van Dam P, Vermeulen P, Van Marck E, et al. Circulating Interleukin-6 Predicts Survival in Patients With Metastatic Breast Cancer. Int J Cancer (2003) 103(5):642-6. doi: 10.1002/ijc.10833

68. Feng W, Madajka M, Kerr BA, Mahabeleshwar GH, Whiteheart SW, Byzova TV. A Novel Role for Platelet Secretion in Angiogenesis: Mediating Bone Marrow-Derived Cell Mobilization and Homing. Blood (2011) 117 (14):3893-902. doi: 10.1182/blood-2010-08-304808

69. Kuznetsov HS, Marsh T, Markens BA, Castano Z, Greene-Colozzi A, Hay SA, et al. Identification of Luminal Breast Cancers That Establish a TumorSupportive Macroenvironment Defined by Proangiogenic Platelets and Bone Marrow-Derived Cells. Cancer Discovery (2012) 2(12):1150-65. doi: 10.1158/2159-8290.CD-12-0216

70. Bauer AT, Suckau J, Frank K, Desch A, Goertz L, Wagner AH, et al. Von Willebrand Factor Fibers Promote Cancer-Associated Platelet Aggregation in Malignant Melanoma of Mice and Humans. Blood (2015) 125(20):315363. doi: 10.1182/blood-2014-08-595686

71. Wojtukiewicz MZ, Sierko E, Hempel D, Tucker SC, Honn KV. Platelets and Cancer Angiogenesis Nexus. Cancer Metastasis Rev (2017) 36(2):249-62. doi: 10.1007/s10555-017-9673-1

72. Qi J, Goralnick S, Kreutzer DL. Fibrin Regulation of Interleukin-8 Gene Expression in Human Vascular Endothelial Cells. Blood (1997) 90(9):3595602. doi: 10.1182/blood.V90.9.3595

73. Shen J, DiCorleto PE. ADP Stimulates Human Endothelial Cell Migration via P2Y1 Nucleotide Receptor-Mediated Mitogen-Activated Protein Kinase Pathways. Circ Res (2008) 102(4):448-56. doi: 10.1161/ CIRCRESAHA.107.165795

74. Pipili-Synetos E, Papadimitriou E, Maragoudakis ME. Evidence That Platelets Promote Tube Formation by Endothelial Cells on Matrigel. $\mathrm{Br} J$ Pharmacol (1998) 125(6):1252-7. doi: 10.1038/sj.bjp.0702191
75. Trikha M, Zhou Z, Timar J, Raso E, Kennel M, Emmell E, et al. Multiple Roles for Platelet GPIIb/IIIa and Alphavbeta3 Integrins in Tumor Growth, Angiogenesis, and Metastasis. Cancer Res (2002) 62(10):2824-33.

76. Varner JA, Nakada MT, Jordan RE, Coller BS. Inhibition of Angiogenesis and Tumor Growth by Murine 7E3, the Parent Antibody of C7E3 Fab (Abciximab; ReoPro). Angiogenesis (1999) 3(1):53-60. doi: 10.1023/ A:1009019223744

77. Huang Z, Miao X, Patarroyo M, Nilsson GP, Pernow J, Li N. Tetraspanin CD151 and Integrin Alpha6beta1 Mediate Platelet-Enhanced Endothelial Colony Forming Cell Angiogenesis. J Thromb Haemost (2016) 14(3):606-18. doi: $10.1111 /$ jth. 13248

78. Dewitte A, Tanga A, Villeneuve J, Lepreux S, Ouattara A, Desmouliere A, et al. New Frontiers for Platelet CD154. Exp Hematol Oncol (2015) 4:6. doi: 10.1186/s40164-015-0001-6

79. Garcia BA, Smalley DM, Cho H, Shabanowitz J, Ley K, Hunt DF. The Platelet Microparticle Proteome. J Proteome Res (2005) 4(5):1516-21. doi: 10.1021/pr0500760

80. Zmigrodzka M, Guzera M, Miskiewicz A, Jagielski D, Winnicka A. The Biology of Extracellular Vesicles With Focus on Platelet Microparticles and Their Role in Cancer Development and Progression. Tumour Biol (2016) 37 (11):14391-401. doi: 10.1007/s13277-016-5358-6

81. Goubran H, Sabry W, Kotb R, Seghatchian J, Burnouf T. Platelet Microparticles and Cancer: An Intimate Cross-Talk. Transfus Apher Sci (2015) 53(2):168-72. doi: 10.1016/j.transci.2015.10.014

82. Kim HK, Song KS, Park YS, Kang YH, Lee YJ, Lee KR, et al. Elevated Levels of Circulating Platelet Microparticles, VEGF, IL-6 and RANTES in Patients With Gastric Cancer: Possible Role of a Metastasis Predictor. Eur J Cancer (2003) 39(2):184-91. doi: 10.1016/S0959-8049(02)00596-8

83. Miao X, Rahman MF, Jiang L, Min Y, Tan S, Xie H, et al. Thrombin-Reduced miR-27b Attenuates Platelet Angiogenic Activities In Vitro via Enhancing Platelet Synthesis of Anti-Angiogenic Thrombospondin-1. J Thromb Haemost (2018) 16(4):791-801. doi: 10.1111/jth.13978

84. Anene C, Graham AM, Boyne J, Roberts W. Platelet Microparticle Delivered microRNA-Let-7a Promotes the Angiogenic Switch. Biochim Biophys Acta Mol Basis Dis (2018) 1864(8):2633-43. doi: 10.1016/j.bbadis.2018.04.013

85. Bertozzi CC, Schmaier AA, Mericko P, Hess PR, Zou Z, Chen M, et al. Platelets Regulate Lymphatic Vascular Development Through CLEC-2-SLP-76 Signaling. Blood (2010) 116(4):661-70. doi: 10.1182/blood-2010-02-270876

86. Haining EJ, Lowe KL, Wichaiyo S, Kataru RP, Nagy Z, Kavanagh DP, et al. Lymphatic Blood Filling in CLEC-2-Deficient Mouse Models. Platelets (2020) 32(3):352-67. doi: 10.1080/09537104.2020.1734784

87. Ge H, Luo H. Overview of Advances in Vasculogenic Mimicry - a Potential Target for Tumor Therapy. Cancer Manag Res (2018) 10:2429-37. doi: 10.2147/CMAR.S164675

88. Martini C, Thompson EJ, Hyslop SR, Cockshell MP, Dale BJ, Ebert LM, et al. Platelets Disrupt Vasculogenic Mimicry by Cancer Cells. Sci Rep (2020) 10 (1):5869. doi: 10.1038/s41598-020-62648-x

89. Ho-Tin-Noe B, Goerge T, Cifuni SM, Duerschmied D, Wagner DD. Platelet Granule Secretion Continuously Prevents Intratumor Hemorrhage. Cancer Res (2008) 68(16):6851-8. doi: 10.1158/0008-5472.CAN-08-0718

90. Ho-Tin-Noe B, Carbo C, Demers M, Cifuni SM, Goerge T, Wagner DD. Innate Immune Cells Induce Hemorrhage in Tumors During Thrombocytopenia. Am J Pathol (2009) 175(4):1699-708. doi: 10.2353/ ajpath.2009.090460

91. Volz J, Mammadova-Bach E, Gil-Pulido J, Nandigama R, Remer K, Sorokin $\mathrm{L}$, et al. Inhibition of Platelet GPVI Induces Intratumor Hemorrhage and Increases Efficacy of Chemotherapy in Mice. Blood (2019) 133(25):2696706. doi: 10.1182/blood.2018877043

92. Demers M, Ho-Tin-Noe B, Schatzberg D, Yang JJ, Wagner DD. Increased Efficacy of Breast Cancer Chemotherapy in Thrombocytopenic Mice. Cancer Res (2011) 71(5):1540-9. doi: 10.1158/0008-5472.CAN-10-2038

93. Zhang Y, Cedervall J, Hamidi A, Herre M, Viitaniemi K, D’Amico G, et al. Platelet-Specific PDGFB Ablation Impairs Tumor Vessel Integrity and Promotes Metastasis. Cancer Res (2020) 80(16):3345-58. doi: 10.1158/ 0008-5472.CAN-19-3533

94. Ho-Tin-Noe B, Boulaftali Y, Camerer E. Platelets and Vascular Integrity: How Platelets Prevent Bleeding in Inflammation. Blood (2018) 131(3):27788. doi: 10.1182/blood-2017-06-742676 
95. Loges S, Schmidt T, Carmeliet P. Mechanisms of Resistance to AntiAngiogenic Therapy and Development of Third-Generation AntiAngiogenic Drug Candidates. Genes Cancer (2010) 1(1):12-25. doi: $10.1177 / 1947601909356574$

96. Labelle M, Hynes RO. The Initial Hours of Metastasis: The Importance of Cooperative Host-Tumor Cell Interactions During Hematogenous Dissemination. Cancer Discov (2012) 2(12):1091-9. doi: 10.1158/21598290.CD-12-0329

97. Strilic B, Offermanns S. Intravascular Survival and Extravasation of Tumor Cells. Cancer Cell (2017) 32(3):282-93. doi: 10.1016/j.ccell.2017.07.001

98. Gasic GJ, Gasic TB, Stewart CC. Antimetastatic Effects Associated With Platelet Reduction. Proc Natl Acad Sci USA (1968) 61(1):46-52. doi: 10.1073/ pnas.61.1.46

99. Camerer E, Qazi AA, Duong DN, Cornelissen I, Advincula R, Coughlin SR. Platelets, Protease-Activated Receptors, and Fibrinogen in Hematogenous Metastasis. Blood (2004) 104(2):397-401. doi: 10.1182/blood-2004-02-0434

100. Luzzi KJ, MacDonald IC, Schmidt EE, Kerkvliet N, Morris VL, Chambers AF, et al. Multistep Nature of Metastatic Inefficiency: Dormancy of Solitary Cells After Successful Extravasation and Limited Survival of Early Micrometastases. Am J Pathol (1998) 153(3):865-73. doi: 10.1016/S00029440(10)65628-3

101. Nieswandt B, Hafner M, Echtenacher B, Mannel DN. Lysis of Tumor Cells by Natural Killer Cells in Mice Is Impeded by Platelets. Cancer Res (1999) 59 (6):1295-300.

102. Palumbo JS, Talmage KE, Massari JV, La Jeunesse CM, Flick MJ, Kombrinck KW, et al. Platelets and Fibrin(Ogen) Increase Metastatic Potential by Impeding Natural Killer Cell-Mediated Elimination of Tumor Cells. Blood (2005) 105(1):178-85. doi: 10.1182/blood-2004-06-2272

103. Coupland LA, Chong BH, Parish CR. Platelets and P-Selectin Control Tumor Cell Metastasis in an Organ-Specific Manner and Independently of NK Cells. Cancer Res (2012) 72(18):4662-71. doi: 10.1158/0008-5472.CAN11-4010

104. Placke T, Orgel M, Schaller M, Jung G, Rammensee HG, Kopp HG, et al. Platelet-Derived MHC Class I Confers a Pseudonormal Phenotype to Cancer Cells That Subverts the Antitumor Reactivity of Natural Killer Immune Cells. Cancer Res (2012) 72(2):440-8. doi: 10.1158/0008-5472.CAN-11-1872

105. Maurer S, Kropp KN, Klein G, Steinle A, Haen SP, Walz JS, et al. PlateletMediated Shedding of NKG2D Ligands Impairs NK Cell ImmuneSurveillance of Tumor Cells. Oncoimmunology (2018) 7(2):e1364827. doi: 10.1080/2162402X.2017.1364827

106. Assoian RK, Sporn MB. Type Beta Transforming Growth Factor in Human Platelets: Release During Platelet Degranulation and Action on Vascular Smooth Muscle Cells. J Cell Biol (1986) 102(4):1217-23. doi: 10.1083/jcb.102.4.1217

107. Labelle M, Begum S, Hynes RO. Direct Signaling Between Platelets and Cancer Cells Induces an Epithelial-Mesenchymal-Like Transition and Promotes Metastasis. Cancer Cell (2011) 20(5):576-90. doi: 10.1016/ j.ccr.2011.09.009

108. Rachidi S, Metelli A, Riesenberg B, Wu BX, Nelson MH, Wallace C, et al. Platelets Subvert T Cell Immunity Against Cancer via GARP-TGFbeta Axis. Sci Immunol (2017) 2(11):eaai7911. doi: 10.1126/sciimmunol.aai7911

109. Kopp HG, Placke T, Salih HR. Platelet-Derived Transforming Growth Factor-Beta Down-Regulates NKG2D Thereby Inhibiting Natural Killer Cell Antitumor Reactivity. Cancer Res (2009) 69(19):7775-83. doi: 10.1158/0008-5472.CAN-09-2123

110. Lee JC, Lee KM, Kim DW, Heo DS. Elevated TGF-Betal Secretion and DownModulation of NKG2D Underlies Impaired NK Cytotoxicity in Cancer Patients. J Immunol (2004) 172(12):7335-40. doi: 10.4049/jimmunol.172.12.7335

111. Metelli A, Wu BX, Riesenberg B, Guglietta S, Huck JD, Mills C, et al. Thrombin Contributes to Cancer Immune Evasion via Proteolysis of Platelet-Bound GARP to Activate LTGF-Beta. Sci Transl Med (2020) 12 (525):eaay4860. doi: 10.1126/scitranslmed.aay4860

112. Huynh LK, Hipolito CJ, Ten Dijke P. A Perspective on the Development of TGF-Beta Inhibitors for Cancer Treatment. Biomolecules (2019) 9(11):743. doi: 10.3390/biom9110743

113. Kalos $\mathrm{M}$, June $\mathrm{CH}$. Adoptive $\mathrm{T}$ Cell Transfer for Cancer Immunotherapy in the Era of Synthetic Biology. Immunity (2013) 39(1):49-60. doi: 10.1016/ j.immuni.2013.07.002
114. Yang J, Antin P, Berx G, Blanpain C, Brabletz T, Bronner M, et al. Guidelines and Definitions for Research on Epithelial-Mesenchymal Transition. Nat Rev Mol Cell Biol (2020) 21(6):341-52. doi: 10.1038/s41580-020-0237-9

115. Zhang Y, Unnithan RVM, Hamidi A, Caja L, Saupe F, Moustakas A, et al. TANK-Binding Kinase 1 Is a Mediator of Platelet-Induced EMT in Mammary Carcinoma Cells. FASEB J (2019) 33(7):7822-32. doi: 10.1096/ fj.201801936RRR

116. Guo Y, Cui W, Pei Y, Xu D. Platelets Promote Invasion and Induce Epithelial to Mesenchymal Transition in Ovarian Cancer Cells by TGF-Beta Signaling Pathway. Gynecol Oncol (2019) 153(3):639-50. doi: 10.1016/j.ygyno. 2019.02.026

117. Xiong G, Chen J, Zhang G, Wang S, Kawasaki K, Zhu J, et al. Hsp47 Promotes Cancer Metastasis by Enhancing Collagen-Dependent Cancer Cell-Platelet Interaction. Proc Natl Acad Sci USA (2020) 117(7):3748-58. doi: 10.1073/pnas.1911951117

118. Zuo XX, Yang Y, Zhang Y, Zhang ZG, Wang XF, Shi YG. Platelets Promote Breast Cancer Cell MCF-7 Metastasis by Direct Interaction: Surface Integrin Alpha2beta1-Contacting-Mediated Activation of Wnt-Beta-Catenin Pathway. Cell Commun Signal (2019) 17(1):142. doi: 10.1186/s12964-0190464-x

119. Steinbrecher KA, Horowitz NA, Blevins EA, Barney KA, Shaw MA, HarmelLaws E, et al. Colitis-Associated Cancer Is Dependent on the Interplay Between the Hemostatic and Inflammatory Systems and Supported by Integrin Alpha(M)beta(2) Engagement of Fibrinogen. Cancer Res (2010) 70(7):2634-43. doi: 10.1158/0008-5472.CAN-09-3465

120. Olson OC, Joyce JA. Cysteine Cathepsin Proteases: Regulators of Cancer Progression and Therapeutic Response. Nat Rev Cancer (2015) 15(12):71229. doi: $10.1038 / \mathrm{nrc} 4027$

121. Andrade SS, Gouvea IE, Silva MC, Castro ED, de Paula CA, Okamoto D, et al. Cathepsin K Induces Platelet Dysfunction and Affects Cell Signaling in Breast Cancer - Molecularly Distinct Behavior of Cathepsin K in Breast Cancer. BMC Cancer (2016) 16:173. doi: 10.1186/s12885-016-2203-7

122. Tang $\mathrm{M}$, Jiang L, Lin $\mathrm{Y}, \mathrm{Wu} \mathrm{X}$, Wang $\mathrm{K}, \mathrm{He} \mathrm{Q}$, et al. Platelet MicroparticleMediated Transfer of miR-939 to Epithelial Ovarian Cancer Cells Promotes Epithelial to Mesenchymal Transition. Oncotarget (2017) 8(57):97464-75. doi: 10.18632/oncotarget.22136

123. McCarty OJ, Mousa SA, Bray PF, Konstantopoulos K. Immobilized Platelets Support Human Colon Carcinoma Cell Tethering, Rolling, and Firm Adhesion Under Dynamic Flow Conditions. Blood (2000) 96(5):1789-97.

124. Bakewell SJ, Nestor P, Prasad S, Tomasson MH, Dowland N, Mehrotra M, et al. Platelet and Osteoclast Beta3 Integrins Are Critical for Bone Metastasis. Proc Natl Acad Sci USA (2003) 100(24):14205-10. doi: 10.1073/ pnas. 2234372100

125. Qi CL, Wei B, Ye J, Yang Y, Li B, Zhang QQ, et al. P-Selectin-Mediated Platelet Adhesion Promotes the Metastasis of Murine Melanoma Cells. PloS One (2014) 9(3):e91320. doi: 10.1371/journal.pone.0091320

126. Kim YJ, Borsig L, Han HL, Varki NM, Varki A. Distinct Selectin Ligands on Colon Carcinoma Mucins Can Mediate Pathological Interactions Among Platelets, Leukocytes, and Endothelium. Am J Pathol (1999) 155(2):461-72. doi: 10.1016/S0002-9440(10)65142-5

127. Zimmerman GA. Two by Two: The Pairings of P-Selectin and P-Selectin Glycoprotein Ligand 1. Proc Natl Acad Sci USA (2001) 98(18):10023-4. doi: 10.1073/pnas.191367898

128. Jain S, Zuka M, Liu J, Russell S, Dent J, Guerrero JA, et al. Platelet Glycoprotein Ib Alpha Supports Experimental Lung Metastasis. Proc Natl Acad Sci USA (2007) 104(21):9024-8. doi: 10.1073/pnas.0700625104

129. Qi Y, Chen W, Liang X, Xu K, Gu X, Wu F, et al. Novel Antibodies Against GPIbalpha Inhibit Pulmonary Metastasis by Affecting vWF-GPIbalpha Interaction. J Hematol Oncol (2018) 11(1):117. doi: 10.1186/s13045-0180659-4

130. Weber MR, Zuka M, Lorger M, Tschan M, Torbett BE, Zijlstra A, et al. Activated Tumor Cell Integrin Alphavbeta3 Cooperates With Platelets to Promote Extravasation and Metastasis From the Blood Stream. Thromb Res (2016) 140 Suppl 1:S27-36. doi: 10.1016/S0049-3848(16)30095-0

131. Pilch J, Habermann R, Felding-Habermann B. Unique Ability of Integrin Alpha (V)Beta 3 to Support Tumor Cell Arrest Under Dynamic Flow Conditions. J Biol Chem (2002) 277(24):21930-8. doi: 10.1074/jbc.M201630200 
132. Morimoto K, Satoh-Yamaguchi K, Hamaguchi A, Inoue Y, Takeuchi M, Okada M, et al. Interaction of Cancer Cells With Platelets Mediated by Necl5/Poliovirus Receptor Enhances Cancer Cell Metastasis to the Lungs. Oncogene (2008) 27(3):264-73. doi: 10.1038/sj.onc.1210645

133. Leblanc R, Lee SC, David M, Bordet JC, Norman DD, Patil R, et al. Interaction of Platelet-Derived Autotaxin With Tumor Integrin Alphavbeta3 Controls Metastasis of Breast Cancer Cells to Bone. Blood (2014) 124(20):3141-50. doi: 10.1182/blood-2014-04-568683

134. Peyruchaud O, Saier L, Leblanc R. Autotaxin Implication in Cancer Metastasis and Autoimunne Disorders: Functional Implication of Binding Autotaxin to the Cell Surface. Cancers (Basel) (2019) 12(1):105. doi: 10.3390/ cancers 12010105

135. Enns A, Korb T, Schluter K, Gassmann P, Spiegel HU, Senninger N, et al. Alphavbeta5-Integrins Mediate Early Steps of Metastasis Formation. Eur J Cancer (2005) 41(7):1065-72. doi: 10.1016/j.ejca.2004.12.031

136. Enns A, Gassmann P, Schluter K, Korb T, Spiegel HU, Senninger N, et al. Integrins Can Directly Mediate Metastatic Tumor Cell Adhesion Within the Liver Sinusoids. J Gastrointest Surg (2004) 8(8):1049-59; discussion 60. doi: 10.1016/j.gassur.2004.08.016

137. Machado EA, Gerard DA, Mitchell JR, Lozzio BB, Lozzio CB. Arrest and Extravasation of Neoplastic Cells. An Electron Microscopy Study of Serial Sections at Sequential Stages. Virchows Arch A Pathol Anat Histol (1982) 396 (1):73-89. doi: 10.1007/BF00428501

138. Im JH, Fu W, Wang H, Bhatia SK, Hammer DA, Kowalska MA, et al. Coagulation Facilitates Tumor Cell Spreading in the Pulmonary Vasculature During Early Metastatic Colony Formation. Cancer Res (2004) 64(23):86139. doi: 10.1158/0008-5472.CAN-04-2078

139. Forster JC, Harriss-Phillips WM, Douglass MJ, Bezak E. A Review of the Development of Tumor Vasculature and its Effects on the Tumor Microenvironment. Hypoxia (Auckl) (2017) 5:21-32. doi: 10.2147/ HP.S133231

140. Chen J, Kos R, Garssen J, Redegeld F. Molecular Insights Into the Mechanism of Necroptosis: The Necrosome As a Potential Therapeutic Target. Cells (2019) 8(12):1486. doi: 10.3390/cells8121486

141. Schumacher D, Strilic B, Sivaraj KK, Wettschureck N, Offermanns S. Platelet-Derived Nucleotides Promote Tumor-Cell Transendothelial Migration and Metastasis via P2Y2 Receptor. Cancer Cell (2013) 24 (1):130-7. doi: 10.1016/j.ccr.2013.05.008

142. Mammadova-Bach E, Gil-Pulido J, Sarukhanyan E, Burkard P, Shityakov S, Schonhart C, et al. Platelet Glycoprotein VI Promotes Metastasis Through Interaction With Cancer Cell-Derived Galectin-3. Blood (2020) 135 (14):1146-60. doi: 10.1182/blood.2019002649

143. Mammadova-Bach E, Mauler M, Braun A, Duerschmied D. Autocrine and Paracrine Regulatory Functions of Platelet Serotonin. Platelets (2018) 29 (6):541-8. doi: 10.1080/09537104.2018.1478072

144. Skolnik G, Bagge U, Blomqvist G, Djarv L, Ahlman H. The Role of Calcium Channels and Serotonin (5-HT2) Receptors for Tumour Cell Lodgement in the Liver. Clin Exp Metastasis (1989) 7(2):169-74. doi: 10.1007/BF01787021

145. Ward Y, Lake R, Faraji F, Sperger J, Martin P, Gilliard C, et al. Platelets Promote Metastasis via Binding Tumor CD97 Leading to Bidirectional Signaling That Coordinates Transendothelial Migration. Cell Rep (2018) 23 (3):808-22. doi: 10.1016/j.celrep.2018.03.092

146. Sarker MH, Hu DE, Fraser PA. Regulation of Cerebromicrovascular Permeability by Lysophosphatidic Acid. Microcirculation (2010) 17(1):3946. doi: 10.1111/j.1549-8719.2010.00001.x

147. Guerrero JA, Bennett C, van der Weyden L, McKinney H, Chin M, Nurden $\mathrm{P}$, et al. Gray Platelet Syndrome: Proinflammatory Megakaryocytes and Alpha-Granule Loss Cause Myelofibrosis and Confer Metastasis Resistance in Mice. Blood (2014) 124(24):3624-35. doi: 10.1182/blood-2014-04-566760

148. Leblanc R, Houssin A, Peyruchaud O. Platelets, Autotaxin and Lysophosphatidic Acid Signalling: Win-Win Factors for Cancer Metastasis. Br J Pharmacol (2018) 175(15):3100-10. doi: 10.1111/bph.14362

149. Giebeler N, Zigrino P. A Disintegrin and Metalloprotease (ADAM): Historical Overview of Their Functions. Toxins (Basel) (2016) 8(4):122. doi: 10.3390/toxins 8040122

150. Mammadova-Bach E, Zigrino P, Brucker C, Bourdon C, Freund M, De Arcangelis A, et al. Platelet Integrin Alpha6betal Controls Lung Metastasis
Through Direct Binding to Cancer Cell-Derived ADAM9. JCI Insight (2016) 1(14):e88245. doi: $10.1172 /$ jci.insight. 88245

151. Giebeler N, Schonefuss A, Landsberg J, Tuting T, Mauch C, Zigrino P. Deletion of ADAM-9 in HGF/CDK4 Mice Impairs Melanoma Development and Metastasis. Oncogene (2017) 36(35):5058-67. doi: 10.1038/onc.2017.162

152. Yu LX, Yan L, Yang W, Wu FQ, Ling Y, Chen SZ, et al. Platelets Promote Tumour Metastasis via Interaction Between TLR4 and Tumour CellReleased High-Mobility Group Box1 Protein. Nat Commun (2014) 5:5256. doi: $10.1038 /$ ncomms 6256

153. Vlodavsky I, Eldor A, Haimovitz-Friedman A, Matzner Y, Ishai-Michaeli R, Lider O, et al. Expression of Heparanase by Platelets and Circulating Cells of the Immune System: Possible Involvement in Diapedesis and Extravasation. Invasion Metastasis (1992) 12(2):112-27.

154. Seizer P, May AE. Platelets and Matrix Metalloproteinases. Thromb Haemost (2013) 110(5):903-9. doi: 10.1160/TH13-02-0113

155. Li R, Ren M, Chen N, Luo M, Deng X, Xia J, et al. Presence of Intratumoral Platelets Is Associated With Tumor Vessel Structure and Metastasis. BMC Cancer (2014) 14:167. doi: 10.1186/1471-2407-14-167

156. Celia-Terrassa T, Kang Y. Metastatic Niche Functions and Therapeutic Opportunities. Nat Cell Biol (2018) 20(8):868-77. doi: 10.1038/s41556018-0145-9

157. Peinado H, Zhang H, Matei IR, Costa-Silva B, Hoshino A, Rodrigues G, et al. Pre-Metastatic Niches: Organ-Specific Homes for Metastases. Nat Rev Cancer (2017) 17(5):302-17. doi: 10.1038/nrc.2017.6

158. Liu S, Jiang M, Zhao Q, Li S, Peng Y, Zhang P, et al. Vascular Endothelial Growth Factor Plays a Critical Role in the Formation of the Pre-Metastatic Niche via Prostaglandin E2. Oncol Rep (2014) 32(6):2477-84. doi: 10.3892/ or.2014.3516

159. Liu Y, Cao X. Characteristics and Significance of the Pre-Metastatic Niche. Cancer Cell (2016) 30(5):668-81. doi: 10.1016/j.ccell.2016.09.011

160. Wang Y, Sun Y, Li D, Zhang L, Wang K, Zuo Y, et al. Platelet P2Y12 Is Involved in Murine Pulmonary Metastasis. PloS One (2013) 8(11):e80780. doi: 10.1371/journal.pone.0080780

161. Labelle M, Begum S, Hynes RO. Platelets Guide the Formation of Early Metastatic Niches. Proc Natl Acad Sci USA (2014) 111(30):E3053-61. doi: 10.1073/pnas. 1411082111

162. Gil-Bernabe AM, Ferjancic S, Tlalka M, Zhao L, Allen PD, Im JH, et al. Recruitment of Monocytes/Macrophages by Tissue Factor-Mediated Coagulation Is Essential For Metastatic Cell Survival and Premetastatic Niche Establishment in Mice. Blood (2012) 119(13):3164-75. doi: 10.1182/ blood-2011-08-376426

163. Li X, Tai HH. Activation of Thromboxane A2 Receptor (TP) Increases the Expression of Monocyte Chemoattractant Protein -1 (MCP-1)/Chemokine (C-C motif) Ligand 2 (CCL2) and Recruits Macrophages to Promote Invasion of Lung Cancer Cells. PLoS One (2013) 8(1):e54073. doi: 10.1371/ journal.pone. 0054073

164. Lucotti S, Cerutti C, Soyer M, Gil-Bernabe AM, Gomes AL, Allen PD, et al. Aspirin Blocks Formation of Metastatic Intravascular Niches by Inhibiting Platelet-Derived COX-1/Thromboxane A2. J Clin Invest (2019) 129(5):184562. doi: 10.1172/JCI121985

165. Catena R, Bhattacharya N, El Rayes T, Wang S, Choi H, Gao D, et al. Bone Marrow-Derived Gr1+ Cells can Generate a Metastasis-Resistant Microenvironment via Induced Secretion of Thrombospondin-1. Cancer Discovery (2013) 3(5):578-89. doi: 10.1158/2159-8290.CD-12-0476

166. Bethany A, Kerr KSH, Shi L, . Willey JS, SotoPantoja DR, Byzova TV. Platelet TSP-1 Controls Prostate Cancer-Induced Osteoclast Differentiation and Bone Marrow-Derived Cell Mobilization Through Tgf $\beta-1$. Am J Clin Exp Urol (2021) 9(1):18-31.

167. Mammadova-Bach E, Jaeken J, Gudermann T, Braun A. Platelets and Defective N-Glycosylation. Int J Mol Sci (2020) 21(16):5630. doi: 10.3390/ ijms 21165630

168. Desgrosellier JS, Cheresh DA. Integrins in Cancer: Biological Implications and Therapeutic Opportunities. Nat Rev Cancer (2010) 10(1):9-22. doi: $10.1038 / \mathrm{nrc} 2748$

169. De Arcangelis A, Hamade H, Alpy F, Normand S, Bruyere E, Lefebvre O, et al. Hemidesmosome Integrity Protects the Colon Against Colitis and Colorectal Cancer. Gut (2017) 66(10):1748-60. doi: 10.1136/gutjnl-2015-310847 
170. Georges-Labouesse E, Messaddeq N, Yehia G, Cadalbert L, Dierich A, Le Meur M. Absence of Integrin Alpha 6 Leads to Epidermolysis Bullosa and Neonatal Death in Mice. Nat Genet (1996) 13(3):370-3. doi: 10.1038/ ng0796-370

171. Durrant TN, van den Bosch MT, Hers I. Integrin Alphaiibbeta3 Outside-in Signaling. Blood (2017) 130(14):1607-19. doi: 10.1182/blood-2017-03773614

172. Gachet C. Antiplatelet Drugs: Which Targets for Which Treatments? J Thromb Haemost (2015) 13 Suppl 1:S313-22. doi: 10.1111/jth.12947

173. Boucharaba A, Serre CM, Gres S, Saulnier-Blache JS, Bordet JC, Guglielmi J, et al. Platelet-Derived Lysophosphatidic Acid Supports the Progression of Osteolytic Bone Metastases in Breast Cancer. J Clin Invest (2004) 114 (12):1714-25. doi: 10.1172/JCI200422123

174. Echtler K, Konrad I, Lorenz M, Schneider S, Hofmaier S, Plenagl F, et al. Platelet GPIIb Supports Initial Pulmonary Retention But Inhibits Subsequent Proliferation of Melanoma Cells During Hematogenic Metastasis. PloS One (2017) 12(3):e0172788. doi: 10.1371/journal.pone.0172788

175. Timar J, Tovari J, Raso E, Meszaros L, Bereczky B, Lapis K. Platelet-Mimicry of Cancer Cells: Epiphenomenon With Clinical Significance. Oncology (2005) 69(3):185-201. doi: 10.1159/000088069

176. Estevez B, Shen B, Du X. Targeting Integrin and Integrin Signaling in Treating Thrombosis. Arterioscler Thromb Vasc Biol (2015) 35(1):24-9. doi: 10.1161/ATVBAHA.114.303411

177. Kim K, Hahm E, Li J, Holbrook LM, Sasikumar P, Stanley RG, et al. Platelet Protein Disulfide Isomerase Is Required for Thrombus Formation But Not for Hemostasis in Mice. Blood (2013) 122(6):1052-61. doi: 10.1182/blood2013-03-492504

178. Zhu G, Zhang Q, Reddy EC, Carrim N, Chen Y, Xu XR, et al. The Integrin PSI Domain Has an Endogenous Thiol Isomerase Function and Is a Novel Target for Antiplatelet Therapy. Blood (2017) 129(13):1840-54. doi: 10.1182/ blood-2016-07-729400

179. Stoll P, Bassler N, Hagemeyer CE, Eisenhardt SU, Chen YC, Schmidt R, et al. Targeting Ligand-Induced Binding Sites on GPIIb/IIIa via Single-Chain Antibody Allows Effective Anticoagulation Without Bleeding Time Prolongation. Arterioscler Thromb Vasc Biol (2007) 27(5):1206-12. doi: 10.1161/ATVBAHA.106.138875

180. Yap ML, McFadyen JD, Wang X, Zia NA, Hohmann JD, Ziegler M, et al. Targeting Activated Platelets: A Unique and Potentially Universal Approach for Cancer Imaging. Theranostics (2017) 7(10):2565-74. doi: 10.7150/ thno. 19900

181. Yap ML, McFadyen JD, Wang X, Ziegler M, Chen YC, Willcox A, et al. Activated Platelets in the Tumor Microenvironment for Targeting of Antibody-Drug Conjugates to Tumors and Metastases. Theranostics (2019) 9(4):1154-69. doi: 10.7150/thno.29146

182. Erpenbeck L, Nieswandt B, Schon M, Pozgajova M, Schon MP. Inhibition of Platelet GPIb Alpha and Promotion of Melanoma Metastasis. J Invest Dermatol (2010) 130(2):576-86. doi: 10.1038/jid.2009.278

183. Kuijpers MJ, Schulte V, Oury C, Lindhout T, Broers J, Hoylaerts MF, et al. Facilitating Roles of Murine Platelet Glycoprotein Ib and Alphaiibbeta3 in Phosphatidylserine Exposure During vWF-Collagen-Induced Thrombus Formation. J Physiol (2004) 558(Pt 2):403-15. doi: 10.1113/ jphysiol.2004.062414

184. Dutting S, Gaits-Iacovoni F, Stegner D, Popp M, Antkowiak A, van Eeuwijk JMM, et al. A Cdc42/RhoA Regulatory Circuit Downstream of Glycoprotein Ib Guides Transendothelial Platelet Biogenesis. Nat Commun (2017) 8:15838. doi: $10.1038 /$ ncomms15838

185. Kleinschnitz C, Pozgajova M, Pham M, Bendszus M, Nieswandt B, Stoll G. Targeting Platelets in Acute Experimental Stroke: Impact of Glycoprotein Ib, VI, and IIb/IIIa Blockade on Infarct Size, Functional Outcome, and Intracranial Bleeding. Circulation (2007) 115(17):2323-30. doi: 10.1161/ CIRCULATIONAHA.107.691279

186. Malehmir M, Pfister D, Gallage S, Szydlowska M, Inverso D, Kotsiliti E, et al. Platelet GPIbalpha Is a Mediator and Potential Interventional Target for NASH and Subsequent Liver Cancer. Nat Med (2019) 25(4):641-55. doi: 10.1038/s41591-019-0379-5

187. Nieswandt B, Bergmeier W, Rackebrandt K, Gessner JE, Zirngibl H. Identification of Critical Antigen-Specific Mechanisms in the Development of Immune Thrombocytopenic Purpura in Mice. Blood (2000) 96(7):2520-7. doi: 10.1182/blood.V96.7.2520

188. Xu M, Li J, Neves MAD, Zhu G, Carrim N, Yu R, et al. GPIbalpha Is Required for Platelet-Mediated Hepatic Thrombopoietin Generation. Blood (2018) 132(6):622-34. doi: 10.1182/blood-2017-12-820779

189. Fontayne A, Meiring M, Lamprecht S, Roodt J, Demarsin E, Barbeaux P, et al. The Humanized Anti-Glycoprotein Ib Monoclonal Antibody H6b4-Fab Is a Potent and Safe Antithrombotic in a High Shear Arterial Thrombosis Model in Baboons. Thromb Haemost (2008) 100(4):670-7. doi: 10.1160/ TH08-02-0073

190. Li TT, Fan ML, Hou SX, Li XY, Barry DM, Jin H, et al. A Novel Snake Venom-Derived GPIb Antagonist, Anfibatide, Protects Mice From Acute Experimental Ischaemic Stroke and Reperfusion Injury. Br J Pharmacol (2015) 172(15):3904-16. doi: 10.1111/bph.13178

191. Lei X, Reheman A, Hou Y, Zhou H, Wang Y, Marshall AH, et al. Anfibatide, a Novel GPIb Complex Antagonist, Inhibits Platelet Adhesion and Thrombus Formation In Vitro and In Vivo in Murine Models of Thrombosis. Thromb Haemost (2014) 111(2):279-89. doi: 10.1160/TH1306-0490

192. Maurer E, Tang C, Schaff M, Bourdon C, Receveur N, Ravanat C, et al. Targeting Platelet GPIbbeta Reduces Platelet Adhesion, GPIb Signaling and Thrombin Generation and Prevents Arterial Thrombosis. Arterioscler Thromb Vasc Biol (2013) 33(6):1221-9. doi: 10.1161/ATVBAHA.112.301013

193. Nurden AT. Clinical Significance of Altered Collagen-Receptor Functioning in Platelets With Emphasis on Glycoprotein VI. Blood Rev (2019) 38:100592. doi: $10.1016 /$ j.blre.2019.100592

194. Jain S, Russell S, Ware J. Platelet Glycoprotein VI Facilitates Experimental Lung Metastasis in Syngenic Mouse Models. J Thromb Haemost (2009) 7 (10):1713-7. doi: 10.1111/j.1538-7836.2009.03559.x

195. Foster H, Wilson C, Philippou H, Foster R. Progress Toward a Glycoprotein VI Modulator for the Treatment of Thrombosis. J Med Chem (2020) 63 (21):12213-42. doi: 10.1021/acs.jmedchem.0c00262

196. Ungerer M, Rosport K, Bultmann A, Piechatzek R, Uhland K, Schlieper P, et al. Novel Antiplatelet Drug Revacept (Dimeric Glycoprotein VI-Fc) Specifically and Efficiently Inhibited Collagen-Induced Platelet Aggregation Without Affecting General Hemostasis in Humans. Circulation (2011) 123 (17):1891-9. doi: 10.1161/CIRCULATIONAHA.110.980623

197. Dovizio M, Maier TJ, Alberti S, Di Francesco L, Marcantoni E, Munch G, et al. Pharmacological Inhibition of Platelet-Tumor Cell Cross-Talk Prevents Platelet-Induced Overexpression of Cyclooxygenase-2 in HT29 Human Colon Carcinoma Cells. Mol Pharmacol (2013) 84(1):25-40. doi: 10.1124/ mol.113.084988

198. Schattner M, Rabinovich GA. Galectins: New Agonists of Platelet Activation. Biol Chem (2013) 394(7):857-63. doi: 10.1515/hsz-2013-0108

199. Etulain J, Negrotto S, Tribulatti MV, Croci DO, Carabelli J, Campetella O, et al. Control of Angiogenesis by Galectins Involves the Release of PlateletDerived Proangiogenic Factors. PloS One (2014) 9(4):e96402. doi: 10.1371/ journal.pone.0096402

200. Mammadova-Bach E, Ollivier V, Loyau S, Schaff M, Dumont B, Favier R, et al. Platelet Glycoprotein VI Binds to Polymerized Fibrin and Promotes Thrombin Generation. Blood (2015) 126(5):683-91. doi: 10.1182/blood-2015-02-629717

201. Alshehri OM, Hughes CE, Montague S, Watson SK, Frampton J, Bender M, et al. Fibrin Activates GPVI in Human and Mouse Platelets. Blood (2015) 126 (13):1601-8. doi: 10.1182/blood-2015-04-641654

202. Induruwa I, Moroi M, Bonna A, Malcor JD, Howes JM, Warburton EA, et al. Platelet Collagen Receptor Glycoprotein VI-Dimer Recognizes Fibrinogen and Fibrin Through Their D-Domains, Contributing to Platelet Adhesion and Activation During Thrombus Formation. J Thromb Haemost (2018) 16 (2):389-404. doi: 10.1111/jth.13919

203. Howes JM, Pugh N, Hamaia SW, Jung SM, Knauper V, Malcor JD, et al. MMP-13 Binds to Platelet Receptors Alphaiibbeta3 and GPVI and Impairs Aggregation and Thrombus Formation. Res Pract Thromb Haemost (2018) 2 (2):370-9. doi: $10.1002 /$ rth2.12088

204. Jadoui S, Le Chapelain O, Ollivier V, Mostefa-Kara A, Di Meglio L, Dupont $\mathrm{S}$, et al. Glenzocimab Does Not Impact Glycoprotein VI-Dependent Inflammatory Haemostasis. Haematologica (2020). Online ahead of print. doi: 10.3324 /haematol.2020.270439 
205. Jandrot-Perrus M, Hermans C, Mezzano D. Platelet Glycoprotein VI Genetic Quantitative and Qualitative Defects. Platelets (2019) 30(6):708-13. doi: 10.1080/09537104.2019.1610166

206. Shirai T, Inoue O, Tamura S, Tsukiji N, Sasaki T, Endo H, et al. C-Type Lectin-Like Receptor 2 Promotes Hematogenous Tumor Metastasis and Prothrombotic State in Tumor-Bearing Mice. J Thromb Haemost (2017) 15 (3):513-25. doi: 10.1111/jth.13604

207. Kato Y, Kaneko MK. A Cancer-Specific Monoclonal Antibody Recognizes the Aberrantly Glycosylated Podoplanin. Sci Rep (2014) 4:5924. doi: 10.1038/ srep05924

208. Xu M, Wang X, Pan Y, Zhao X, Yan B, Ruan C, et al. Blocking Podoplanin Suppresses Growth and Pulmonary Metastasis of Human Malignant Melanoma. BMC Cancer (2019) 19(1):599. doi: 10.1186/s12885-019-5808-9

209. Bender M, May F, Lorenz V, Thielmann I, Hagedorn I, Finney BA, et al. Combined In Vivo Depletion of Glycoprotein VI and C-Type Lectin-Like Receptor 2 Severely Compromises Hemostasis and Abrogates Arterial Thrombosis in Mice. Arterioscler Thromb Vasc Biol (2013) 33(5):926-34. doi: 10.1161/ATVBAHA.112.300672

210. Sekiguchi T, Takemoto A, Takagi S, Takatori K, Sato S, Takami M, et al. Targeting a Novel Domain in Podoplanin for Inhibiting Platelet-Mediated Tumor Metastasis. Oncotarget (2016) 7(4):3934-46. doi: 10.18632/ oncotarget.6598

211. Tseng CP, Huang YL, Chang YW, Liao HR, Chen YL, Hsieh PW. Polysaccharide-Containing Fraction From Artemisia Argyi Inhibits Tumor Cell-Induced Platelet Aggregation by Blocking Interaction of Podoplanin With C-Type Lectin-Like Receptor 2. J Food Drug Anal (2020) 28(1):115-23. doi: 10.1016/j.jfda.2019.08.002

212. Bruserud O. The Snake Venom Rhodocytin From Calloselasma Rhodostoma- A Clinically Important Toxin and a Useful Experimental Tool for Studies of C-Type Lectin-Like Receptor 2 (CLEC-2). Toxins (Basel) (2013) 5(4):665-74. doi: 10.3390/toxins5040665

213. Sasaki T, Shirai T, Tsukiji N, Otake S, Tamura S, Ichikawa J, et al. Functional Characterization of Recombinant Snake Venom Rhodocytin: Rhodocytin Mutant Blocks CLEC-2/Podoplanin-Dependent Platelet Aggregation and Lung Metastasis. J Thromb Haemost (2018) 16(5):960-72. doi: 10.1111/ jth.13987

214. Rucker D, Dhamoon AS. Physiology, Thromboxane A2. Treasure Island (FL: StatPearls (2021).

215. Patrignani P, Patrono C. Aspirin, Platelet Inhibition and Cancer Prevention. Platelets (2018) 29(8):779-85. doi: 10.1080/09537104.2018.1492105

216. Patrignani P, Patrono C. Aspirin and Cancer. J Am Coll Cardiol (2016) 68 (9):967-76. doi: 10.1016/j.jacc.2016.05.083

217. Crofford LJ. COX-1 and COX-2 Tissue Expression: Implications and Predictions. J Rheumatol Suppl (1997) 49:15-9.

218. Koki AT, Masferrer JL. Celecoxib: A Specific COX-2 Inhibitor With Anticancer Properties. Cancer Control (2002) 9(2 Suppl):28-35. doi: $10.1177 / 107327480200902 S 04$

219. Gasic GJ, Gasic TB, Galanti N, Johnson T, Murphy S. Platelet-Tumor-Cell Interactions in Mice. The Role of Platelets in the Spread of Malignant Disease. Int J Cancer (1973) 11(3):704-18. doi: 10.1002/ijc.2910110322

220. Pacchiarini L, Serra L, Grignani G, Gamba G, Gorini M. In Vitro Effect of Culture Fluids From Neoplastic Tissues on Platelet Aggregation. II. Experimental Tumors. Boll Soc Ital Biol Sper (1982) 58(13):854-9.

221. Bradley CJ, Dauer RJ, Thurlow PJ, Connellan JM. Characterization of Platelet Aggregation Induced by the Human Carcinosarcoma Colo 526: Role of Platelet Activation, Tumor Cell Cytoskeleton and Tumor Cell Plasma Membrane. Pathology (1997) 29(2):189-95. doi: 10.1080/00313029700169844

222. Rinder CS, Student LA, Bonan JL, Rinder HM, Smith BR. Aspirin Does Not Inhibit Adenosine Diphosphate-Induced Platelet Alpha-Granule Release. Blood (1993) 82(2):505-12.

223. Kune GA, Kune S, Watson LF. Colorectal Cancer Risk, Chronic Illnesses, Operations, and Medications: Case Control Results From the Melbourne Colorectal Cancer Study. Cancer Res (1988) 48(15):4399-404.

224. Benamouzig R, Deyra J, Martin A, Girard B, Jullian E, Piednoir B, et al. Daily Soluble Aspirin and Prevention of Colorectal Adenoma Recurrence: OneYear Results of the APACC Trial. Gastroenterology (2003) 125(2):328-36. doi: 10.1016/S0016-5085(03)00887-4
225. Baron JA, Cole BF, Sandler RS, Haile RW, Ahnen D, Bresalier R, et al. A Randomized Trial of Aspirin to Prevent Colorectal Adenomas. N Engl J Med (2003) 348(10):891-9. doi: 10.1056/NEJMoa021735

226. Ishikawa $\mathrm{H}$, Wakabayashi K, Suzuki S, Mutoh M, Hirata K, Nakamura T, et al. Preventive Effects of Low-Dose Aspirin on Colorectal Adenoma Growth in Patients With Familial Adenomatous Polyposis: Double-Blind, Randomized Clinical Trial. Cancer Med (2013) 2(1):50-6. doi: 10.1002/ cam 4.46

227. Burn J, Gerdes AM, Macrae F, Mecklin JP, Moeslein G, Olschwang S, et al. Long-Term Effect of Aspirin on Cancer Risk in Carriers of Hereditary Colorectal Cancer: An Analysis From the CAPP2 Randomised Controlled Trial. Lancet (2011) 378(9809):2081-7.

228. Frouws MA, Bastiaannet E, Langley RE, Chia WK, van Herk-Sukel MP, Lemmens VE, et al. Effect of Low-Dose Aspirin Use on Survival of Patients With Gastrointestinal Malignancies; an Observational Study. $\mathrm{Br} J$ Cancer (2017) 116(3):405-13. doi: 10.1038/bjc.2016.425

229. Risch HA, Lu L, Streicher SA, Wang J, Zhang W, Ni Q, et al. Aspirin Use and Reduced Risk of Pancreatic Cancer. Cancer Epidemiol Biomarkers Prev (2017) 26(1):68-74. doi: 10.1158/1055-9965.EPI-16-0508

230. Rothwell PM, Price JF, Fowkes FG, Zanchetti A, Roncaglioni MC, Tognoni G, et al. Short-Term Effects of Daily Aspirin on Cancer Incidence, Mortality, and Non-Vascular Death: Analysis of the Time Course of Risks and Benefits in 51 Randomised Controlled Trials. Lancet (2012) 379(9826):1602-12. doi: 10.1016/S0140-6736(11)61720-0

231. Rothwell PM, Wilson M, Price JF, Belch JF, Meade TW, Mehta Z. Effect of Daily Aspirin on Risk of Cancer Metastasis: A Study of Incident Cancers During Randomised Controlled Trials. Lancet (2012) 379(9826):1591-601. doi: 10.1016/S0140-6736(12)60209-8

232. Rothwell PM, Wilson M, Elwin CE, Norrving B, Algra A, Warlow CP, et al. Long-Term Effect of Aspirin on Colorectal Cancer Incidence and Mortality: 20-Year Follow-Up of Five Randomised Trials. Lancet (2010) 376 (9754):1741-50. doi: 10.1016/S0140-6736(10)61543-7

233. Rothwell PM, Fowkes FG, Belch JF, Ogawa H, Warlow CP, Meade TW. Effect of Daily Aspirin on Long-Term Risk of Death Due to Cancer: Analysis of Individual Patient Data From Randomised Trials. Lancet (2011) 377 (9759):31-41. doi: 10.1016/S0140-6736(10)62110-1

234. Warner TD, Nylander S, Whatling C. Anti-Platelet Therapy: CycloOxygenase Inhibition and the Use of Aspirin With Particular Regard to Dual Anti-Platelet Therapy. Br J Clin Pharmacol (2011) 72(4):619-33. doi: 10.1111/j.1365-2125.2011.03943.x

235. Evangelista V, Manarini S, Di Santo A, Capone ML, Ricciotti E, Di Francesco L, et al. De Novo Synthesis of Cyclooxygenase-1 Counteracts the Suppression of Platelet Thromboxane Biosynthesis by Aspirin. Circ Res (2006) 98(5):5935. doi: 10.1161/01.RES.0000214553.37930.3e

236. Patrignani P, Tacconelli S, Piazuelo E, Di Francesco L, Dovizio M, Sostres C, et al. Reappraisal of the Clinical Pharmacology of Low-Dose Aspirin by Comparing Novel Direct and Traditional Indirect Biomarkers of Drug Action. J Thromb Haemost (2014) 12(8):1320-30. doi: 10.1111/jth.12637

237. Ornelas A, Zacharias-Millward N, Menter DG, Davis JS, Lichtenberger L, Hawke D, et al. Beyond COX-1: The Effects of Aspirin on Platelet Biology and Potential Mechanisms of Chemoprevention. Cancer Metastasis Rev (2017) 36(2):289-303. doi: 10.1007/s10555-017-9675-Z

238. Lecomte M, Laneuville O, Ji C, DeWitt DL, Smith WL. Acetylation of Human Prostaglandin Endoperoxide Synthase-2 (Cyclooxygenase-2) by Aspirin. J Biol Chem (1994) 269(18):13207-15. doi: 10.1016/S0021-9258(17)36820-5

239. Cazenave JP, Gachet C. Anti-Platelet Drugs: Do They Affect Megakaryocytes? Baillieres Clin Haematol (1997) 10(1):163-80. doi: 10.1016/S0950-3536(97)80056-X

240. Lucotti S, Muschel RJ. Platelets and Metastasis: New Implications of an Old Interplay. Front Oncol (2020) 10:1350. doi: 10.3389/fonc.2020.01350

241. Oshima M, Dinchuk JE, Kargman SL, Oshima H, Hancock B, Kwong E, et al. Suppression of Intestinal Polyposis in Apc Delta716 Knockout Mice by Inhibition of Cyclooxygenase 2 (COX-2). Cell (1996) 87(5):803-9. doi: 10.1016/S0092-8674(00)81988-1

242. Chan AT, Ogino S, Fuchs CS. Aspirin and the Risk of Colorectal Cancer in Relation to the Expression of COX-2. N Engl J Med (2007) 356(21):2131-42. doi: 10.1056/NEJMoa067208 
243. Sciulli MG, Filabozzi P, Tacconelli S, Padovano R, Ricciotti E, Capone ML, et al. Platelet Activation in Patients With Colorectal Cancer. Prostaglandins Leukot Essent Fatty Acids (2005) 72(2):79-83. doi: 10.1016/ j.plefa.2004.10.006

244. Stark LA, Reid K, Sansom OJ, Din FV, Guichard S, Mayer I, et al. Aspirin Activates the NF-kappaB Signalling Pathway and Induces Apoptosis in Intestinal Neoplasia in Two In Vivo Models of Human Colorectal Cancer. Carcinogenesis (2007) 28(5):968-76. doi: 10.1093/carcin/bgl220

245. Pan MR, Chang HC, Hung WC. Non-Steroidal Anti-Inflammatory Drugs Suppress the ERK Signaling Pathway via Block of Ras/c-Raf Interaction and Activation of MAP Kinase Phosphatases. Cell Signal (2008) 20(6):1134-41. doi: 10.1016/j.cellsig.2008.02.004

246. Sankaranarayanan R, Kumar DR, Altinoz MA, Bhat GJ. Mechanisms of Colorectal Cancer Prevention by Aspirin-A Literature Review and Perspective on the Role of COX-Dependent and -Independent Pathways. Int J Mol Sci (2020) 21(23):9018. doi: 10.3390/ijms21239018

247. Bos CL, Kodach LL, van den Brink GR, Diks SH, van Santen MM, Richel DJ, et al. Effect of Aspirin on the Wnt/beta-Catenin Pathway Is Mediated via Protein Phosphatase 2A. Oncogene (2006) 25(49):6447-56. doi: 10.1038/ sj.onc. 1209658

248. Lichtenberger LM, Romero JJ, Dial EJ. Surface Phospholipids in Gastric Injury and Protection When a Selective Cyclooxygenase-2 Inhibitor (Coxib) Is Used in Combination With Aspirin. Br J Pharmacol (2007) 150(7):913-9. doi: $10.1038 /$ sj.bjp.0707176

249. Lichtenberger LM, Fang D, Bick RJ, Poindexter BJ, Phan T, Bergeron AL, et al. Unlocking Aspirin's Chemopreventive Activity: Role of Irreversibly Inhibiting Platelet Cyclooxygenase-1. Cancer Prev Res (Phila) (2017) 10 (2):142-52. doi: 10.1158/1940-6207.CAPR-16-0241

250. Dovizio M, Tacconelli S, Sostres C, Ricciotti E, Patrignani P. Mechanistic and Pharmacological Issues of Aspirin as an Anticancer Agent. Pharmaceuticals (Basel) (2012) 5(12):1346-71. doi: 10.3390/ph5121346

251. Sitia G, Aiolfi R, Di Lucia P, Mainetti M, Fiocchi A, Mingozzi F, et al. Antiplatelet Therapy Prevents Hepatocellular Carcinoma and Improves Survival in a Mouse Model of Chronic Hepatitis B. Proc Natl Acad Sci USA (2012) 109(32):E2165-72. doi: 10.1073/pnas.1209182109

252. Gachet C. Regulation of Platelet Functions by P2 Receptors. Annu Rev Pharmacol Toxicol (2006) 46:277-300. doi: 10.1146/annurev.pharmtox.46.120604.141207

253. Gachet C. P2 Receptors, Platelet Function and Pharmacological Implications. Thromb Haemostasis (2008) 99(3):466-72. doi: 10.1160/ TH07-11-0673

254. Cattaneo M. New P2Y(12) Inhibitors. Circulation (2010) 121(1):171-9. doi: 10.1161/CIRCULATIONAHA.109.853069

255. Mezouar S, Darbousset R, Dignat-George F, Panicot-Dubois L, Dubois C. Inhibition of Platelet Activation Prevents the P-Selectin and IntegrinDependent Accumulation of Cancer Cell Microparticles and Reduces Tumor Growth and Metastasis In Vivo. Int J Cancer J Int du Cancer (2015) 136(2):462-75. doi: 10.1002/ijc.28997

256. Gareau AJ, Brien C, Gebremeskel S, Liwski RS, Johnston B, Bezuhly M. Ticagrelor Inhibits Platelet-Tumor Cell Interactions and Metastasis in Human and Murine Breast Cancer. Clin Exp Metastasis (2018) 35(1-2):2535. doi: 10.1007/s10585-018-9874-1

257. Gebremeskel S, LeVatte T, Liwski RS, Johnston B, Bezuhly M. The Reversible P2Y12 Inhibitor Ticagrelor Inhibits Metastasis and Improves Survival in Mouse Models of Cancer. Int J Cancer (2015) 136(1):234-40. doi: 10.1002/ ijc. 28947

258. Cho MS, Noh K, Haemmerle M, Li D, Park H, Hu Q, et al. Role of ADP Receptors on Platelets in the Growth of Ovarian Cancer. Blood (2017) 130 (10):1235-42. doi: 10.1182/blood-2017-02-769893

259. Kamiyama M, Shirai T, Tamura S, Suzuki-Inoue K, Ehata S, Takahashi K, et al. ASK1 Facilitates Tumor Metastasis Through Phosphorylation of an ADP Receptor P2Y12 in Platelets. Cell Death Differ (2017) 24(12):2066-76. doi: $10.1038 / \mathrm{cdd} .2017 .114$

260. Geranpayehvaghei M, Shi Q, Zhao B, Li S, Xu J, Taleb M, et al. Targeting Delivery of Platelets Inhibitor to Prevent Tumor Metastasis. Bioconjug Chem (2019) 30(9):2349-57. doi: 10.1021/acs.bioconjchem.9b00457

261. Elaskalani O, Falasca M, Moran N, Berndt MC, Metharom P. The Role of Platelet-Derived ADP and ATP in Promoting Pancreatic Cancer Cell
Survival and Gemcitabine Resistance. Cancers (Basel) (2017) 9(10):142. doi: $10.3390 /$ cancers9100142

262. Ravishankar D, Albadawi DAI, Chaggar V, Patra PH, Williams HF, Salamah $\mathrm{M}$, et al. Isorhapontigenin, a Resveratrol Analogue Selectively Inhibits ADPStimulated Platelet Activation. Eur J Pharmacol (2019) 862:172627. doi: 10.1016/j.ejphar.2019.172627

263. Denslow A, Switalska M, Jarosz J, Papiernik D, Porshneva K, Nowak M, et al. Clopidogrel in a Combined Therapy With Anticancer Drugs-Effect on Tumor Growth, Metastasis, and Treatment Toxicity: Studies in Animal Models. PloS One (2017) 12(12):e0188740. doi: 10.1371/journal.pone.0188740

264. Gachet C. P2Y(12) Receptors in Platelets and Other Hematopoietic and Non-Hematopoietic Cells. Purinergic Signal (2012) 8(3):609-19. doi: $10.1007 /$ s11302-012-9303-X

265. Su X, Floyd DH, Hughes A, Xiang J, Schneider JG, Uluckan O, et al. The ADP Receptor P2RY12 Regulates Osteoclast Function and Pathologic Bone Remodeling. J Clin Invest (2012) 122(10):3579-92. doi: 10.1172/JCI38576

266. Wiviott SD, Braunwald E, McCabe CH, Montalescot G, Ruzyllo W, Gottlieb $\mathrm{S}$, et al. Prasugrel Versus Clopidogrel in Patients With Acute Coronary Syndromes. N Engl J Med (2007) 357(20):2001-15. doi: 10.1056/ NEJMoa0706482

267. Roe MT, Armstrong PW, Fox KA, White HD, Prabhakaran D, Goodman SG, et al. Prasugrel Versus Clopidogrel for Acute Coronary Syndromes Without Revascularization. N Engl J Med (2012) 367(14):1297-309. doi: 10.1056/ NEJMoa1205512

268. Mauri L, Kereiakes DJ, Yeh RW, Driscoll-Shempp P, Cutlip DE, Steg PG, et al. Twelve or 30 Months of Dual Antiplatelet Therapy After Drug-Eluting Stents. N Engl J Med (2014) 371(23):2155-66. doi: 10.1056/NEJMoa1409312

269. Serebruany VL. Ticagrelor Shift From PLATO to PEGASUS: Vanished Mortality Benefit, Excess Cancer Deaths, Massive Discontinuations, and Overshooting Target Events. Int J Cardiol (2015) 201:508-12. doi: 10.1016/ j.ijcard.2015.08.043

270. Raposeiras-Roubin S, Abu-Assi E, Munoz-Pousa I, Cespon-Fernandez M, Cobas-Paz R, Caneiro-Queija B, et al. Risk of Cancer After an Acute Coronary Syndrome According to the Type of P2Y12 Inhibitor. Thromb Res (2019) 174:51-8. doi: 10.1016/j.thromres.2018.12.014

271. Floyd JS, Serebruany VL. Prasugrel as a Potential Cancer Promoter: Review of the Unpublished Data. Arch Intern Med (2010) 170(12):1078-80. doi: 10.1001/archinternmed.2010.154

272. Stalker TJ, Newman DK, Ma P, Wannemacher KM, Brass LF. Platelet Signaling. Handb Exp Pharmacol (2012) 210):59-85. doi: 10.1007/978-3642-29423-5_3

273. Wojtukiewicz MZ, Hempel D, Sierko E, Tucker SC, Honn KV. ProteaseActivated Receptors (PARs)-Biology and Role in Cancer Invasion and Metastasis. Cancer Metastasis Rev (2015) 34(4):775-96. doi: 10.1007/ s10555-015-9599-4

274. Posma JJ, Grover SP, Hisada Y, Owens AP3rd, Antoniak S, Spronk HM, et al. Roles of Coagulation Proteases and PARs (Protease-Activated Receptors) in Mouse Models of Inflammatory Diseases. Arterioscler Thromb Vasc Biol (2019) 39(1):13-24. doi: 10.1161/ATVBAHA.118.311655

275. Cheng JW. Impact of Selective Platelet Inhibition in Reducing Cardiovascular Risk - Role of Vorapaxar. Vasc Health Risk Manag (2016) 12:263-8. doi: 10.2147/VHRM.S81342

276. Aisiku O, Peters CG, De Ceunynck K, Ghosh CC, Dilks JR, Fustolo-Gunnink SF, et al. Parmodulins Inhibit Thrombus Formation Without Inducing Endothelial Injury Caused by Vorapaxar. Blood (2015) 125(12):1976-85. doi: 10.1182/blood-2014-09-599910

277. Covic L, Kuliopulos A. Protease-Activated Receptor 1 as Therapeutic Target in Breast, Lung, and Ovarian Cancer: Pepducin Approach. Int J Mol Sci (2018) 19(8):2237. doi: 10.3390/ijms19082237

278. Zhang P, Gruber A, Kasuda S, Kimmelstiel C, O'Callaghan K, Cox DH, et al. Suppression of Arterial Thrombosis Without Affecting Hemostatic Parameters With a Cell-Penetrating PAR1 Pepducin. Circulation (2012) 126(1):83-91. doi: 10.1161/CIRCULATIONAHA.112.091918

279. Boire A, Covic L, Agarwal A, Jacques S, Sherifi S, Kuliopulos A. PAR1 Is a Matrix Metalloprotease-1 Receptor That Promotes Invasion and Tumorigenesis of Breast Cancer Cells. Cell (2005) 120(3):303-13. doi: 10.1016/j.cell.2004.12.018 
280. Ma SN, Mao ZX, Wu Y, Liang MX, Wang DD, Chen X, et al. The AntiCancer Properties of Heparin and its Derivatives: A Review and Prospect. Cell Adh Migr (2020) 14(1):118-28. doi: 10.1080/19336918.2020.1767489

281. Dimakakos EP, Vathiotis I, Syrigos K. The Role of Tinzaparin in Oncology. Clin Appl Thromb Hemost (2018) 24(5):697-707. doi: 10.1177/1076029617729215

282. Zhang C, Liu Y, Gao Y, Shen J, Zheng S, Wei M, et al. Modified Heparins Inhibit Integrin Alpha(IIb)beta(3) Mediated Adhesion of Melanoma Cells to Platelets In Vitro and In Vivo. Int J Cancer (2009) 125(9):2058-65. doi: $10.1002 / \mathrm{ijc} .24561$

283. Fritzsche J, Simonis D, Bendas G. Melanoma Cell Adhesion can be Blocked by Heparin In Vitro: Suggestion of VLA-4 as a Novel Target for Antimetastatic Approaches. Thromb Haemost (2008) 100(6):1166-75. doi: 10.1160/TH08-05-0332

284. Azab AK, Quang P, Azab F, Pitsillides C, Thompson B, Chonghaile T, et al. P-Selectin Glycoprotein Ligand Regulates the Interaction of Multiple Myeloma Cells With the Bone Marrow Microenvironment. Blood (2012) 119(6):1468-78. doi: 10.1182/blood-2011-07-368050

285. Neumayr LD, Hoppe CC, Brown C. Sickle Cell Disease: Current Treatment and Emerging Therapies. Am J Manag Care (2019) 25(18 Suppl):S335-S43.

286. Gardner RV. Crizanlizumab in Vaso-Occlusive Crisis Caused by Sickle Cell Disease. Drugs Today (Barc) (2020) 56(11):705-14. doi: 10.1358/dot.2020.56.11.3178111

287. Marrugo-Ramirez J, Mir M, Samitier J. Blood-Based Cancer Biomarkers in Liquid Biopsy: A Promising Non-Invasive Alternative to Tissue Biopsy. Int J Mol Sci (2018) 19(10):2877. doi: 10.3390/ijms19102877

288. Peterson JE, Zurakowski D, Italiano JEJr., Michel LV, Connors S, Oenick M, et al. VEGF, PF4 and PDGF Are Elevated in Platelets of Colorectal Cancer Patients. Angiogenesis (2012) 15(2):265-73. doi: 10.1007/s10456-012-9259-z

289. Best MG, Sol N, Kooi I, Tannous J, Westerman BA, Rustenburg F, et al. RNA-Seq of Tumor-Educated Platelets Enables Blood-Based Pan-Cancer, Multiclass, and Molecular Pathway Cancer Diagnostics. Cancer Cell (2015) 28(5):666-76. doi: 10.1016/j.ccell.2015.09.018

290. Best MG, Wesseling P, Wurdinger T. Tumor-Educated Platelets as a Noninvasive Biomarker Source for Cancer Detection and Progression Monitoring. Cancer Res (2018) 78(13):3407-12. doi: 10.1158/00085472.CAN-18-0887

291. Dunbar A, Bolton KL, Devlin SM, Sanchez-Vega F, Gao J, Mones JV, et al. Genomic Profiling Identifies Somatic Mutations Predicting Thromboembolic Risk in Patients With Solid Tumors. Blood (2021) 137(15):2103-13. doi: 10.1182/ blood.2020007488

292. Rak J. Cancer Genes and Blood Clots. Blood (2021) 137(15):1996-7. doi: 10.1182/blood.2020009967

293. Ay C, Simanek R, Vormittag R, Dunkler D, Alguel G, Koder S, et al. High Plasma Levels of Soluble P-Selectin Are Predictive of Venous Thromboembolism in Cancer Patients: Results From the Vienna Cancer and Thrombosis Study (CATS). Blood (2008) 112(7):2703-8. doi: 10.1182/blood-2008-02-142422

294. Lima LG, Monteiro RQ. Activation of Blood Coagulation in Cancer: Implications for Tumour Progression. Biosci Rep (2013) 33(5):e00064. doi: 10.1042/BSR20130057

295. Dai H, Zhou H, Sun Y, Xu Z, Wang S, Feng T, et al. D-Dimer as a Potential Clinical Marker for Predicting Metastasis and Progression in Cancer. BioMed Rep (2018) 9(5):453-7. doi: 10.3892/br.2018.1151

296. Guo R, Yang J, Liu X, Wu J, Chen Y. Increased Von Willebrand Factor Over Decreased ADAMTS-13 Activity Is Associated With Poor Prognosis in Patients With Advanced Non-Small-Cell Lung Cancer. J Clin Lab Anal (2018) 32(1):e22219. doi: 10.1002/jcla.22219

297. Luo Y, Kim HS, Kim M, Lee M, Song YS. Elevated Plasma Fibrinogen Levels and Prognosis of Epithelial Ovarian Cancer: A Cohort Study and MetaAnalysis. J Gynecol Oncol (2017) 28(3):e36. doi: 10.3802/jgo.2017.28.e36

298. Wu J, Fu Z, Liu G, Xu P, Xu J, Jia X. Clinical Significance of Plasma D-Dimer in Ovarian Cancer: A Meta-Analysis. Med (Baltimore) (2017) 96(25):e7062. doi: 10.1097/MD.0000000000007062

299. Geddings JE, Mackman N. Tumor-Derived Tissue Factor-Positive Microparticles and Venous Thrombosis in Cancer Patients. Blood (2013) 122(11):1873-80. doi: 10.1182/blood-2013-04-460139

300. Chatterjee M, Gawaz M. Clinical Significance of Receptor Shedding-Platelet GPVI as an Emerging Diagnostic and Therapeutic Tool. Platelets (2017) 28 (4):362-71. doi: 10.1080/09537104.2016.1227062
301. Assinger A, Schrottmaier WC, Salzmann M, Rayes J. Platelets in Sepsis: An Update on Experimental Models and Clinical Data. Front Immunol (2019) 10:1687. doi: 10.3389/fimmu.2019.01687

302. Stack JR, Madigan A, Helbert L, Dunne E, Gardiner EE, Andrews RK, et al. A Specific Marker of Platelet Activation Is Increased in the Plasma of Subjects With Seropositive Rheumatoid Arthritis. PloS One (2017) 12(11):e0188027. doi: 10.1371/journal.pone.0188027

303. Ahmed MU, Kaneva V, Loyau S, Nechipurenko D, Receveur N, Le Bris M, et al. Pharmacological Blockade of Glycoprotein VI Promotes Thrombus Disaggregation in the Absence of Thrombin. Arterioscler Thromb Vasc Biol (2020) 40(9):2127-42. doi: 10.1161/ATVBAHA.120.314301

304. Montague SJ, Delierneux C, Lecut C, Layios N, Dinsdale RJ, Lee CS, et al. Soluble GPVI Is Elevated in Injured Patients: Shedding Is Mediated by Fibrin Activation of GPVI. Blood Adv (2018) 2(3):240-51. doi: 10.1182/ bloodadvances.2017011171

305. Lip GY, Chin BS, Blann AD. Cancer and the Prothrombotic State. Lancet Oncol (2002) 3(1):27-34. doi: 10.1016/S1470-2045(01)00619-2

306. Sahni S, Krisp C, Molloy MP, Nahm C, Maloney S, Gillson J, et al. PSMD11, PTPRM and PTPRB as Novel Biomarkers of Pancreatic Cancer Progression. Biochim Biophys Acta Gen Subj (2020) 1864(11):129682. doi: 10.1016/ j.bbagen.2020.129682

307. Elaskalani O, Berndt MC, Falasca M, Metharom P. Targeting Platelets for the Treatment of Cancer. Cancers (Basel) (2017) 9(7):94. doi: 10.3390/ cancers 9070094

308. Ibele GM, Kay NE, Johnson GJ, Jacob HS. Human Platelets Exert Cytotoxic Effects on Tumor Cells. Blood (1985) 65(5):1252-5.

309. Sagawa T, Tominaga A, Kodama T, Okada M. Cytotoxicity of Unstimulated and Thrombin-Activated Platelets to Human Tumour Cells. Immunology (1993) 78(4):650-6.

310. Ahmad R, Menezes J, Knafo L, Ahmad A. Activated Human Platelets Express Fas-L and Induce Apoptosis in Fas-Positive Tumor Cells. J Leukoc Biol (2001) 69(1):123-8.

311. Paoli P, Giannoni E, Chiarugi P. Anoikis Molecular Pathways and its Role in Cancer Progression. Biochim Biophys Acta (2013) 1833(12):3481-98. doi: 10.1016/j.bbamcr.2013.06.026

312. Haemmerle M, Taylor ML, Gutschner T, Pradeep S, Cho MS, Sheng J, et al. Platelets Reduce Anoikis and Promote Metastasis by Activating YAP1 Signaling. Nat Commun (2017) 8(1):310. doi: 10.1038/s41467-017-00411-z

313. Carr BI, Cavallini A, D’Alessandro R, Refolo MG, Lippolis C, Mazzocca A, et al. Platelet Extracts Induce Growth, Migration and Invasion in Human Hepatocellular Carcinoma In Vitro. BMC Cancer (2014) 14:43. doi: 10.1186/ 1471-2407-14-43

314. Cho MS, Bottsford-Miller J, Vasquez HG, Stone R, Zand B, Kroll MH, et al. Platelets Increase the Proliferation of Ovarian Cancer Cells. Blood (2012) 120 (24):4869-72. doi: 10.1182/blood-2012-06-438598

315. Haemmerle M, Bottsford-Miller J, Pradeep S, Taylor ML, Choi HJ, Hansen JM, et al. FAK Regulates Platelet Extravasation and Tumor Growth After Antiangiogenic Therapy Withdrawal. J Clin Invest (2016) 126(5):1885-96. doi:10.1172/JCI85086

316. Pucci F, Rickelt S, Newton AP, Garris C, Nunes E, Evavold C, et al. PF4 Promotes Platelet Production and Lung Cancer Growth. Cell Rep (2016) 17 (7):1764-72. doi: 10.1016/j.celrep.2016.10.031

317. Li J, Sharkey CC, Wun B, Liesveld JL, King MR. Genetic Engineering of Platelets to Neutralize Circulating Tumor Cells. J Control Release (2016) 228:38-47. doi: 10.1016/j.jconrel.2016.02.036

318. Hu Q, Sun W, Qian C, Wang C, Bomba HN, Gu Z. Anticancer Platelet-Mimicking Nanovehicles. Adv Mater (2015) 27(44):7043-50. doi: 10.1002/adma.201503323

319. Papa AL, Jiang A, Korin N, Chen MB, Langan ET, Waterhouse A, et al. Platelet Decoys Inhibit Thrombosis and Prevent Metastatic Tumor Formation in Preclinical Models. Sci Transl Med (2019) 11(479):eaau5898. doi: 10.1126/scitranslmed.aau5898

320. Xu P, Zuo H, Zhou R, Wang F, Liu X, Ouyang J, et al. Doxorubicin-Loaded Platelets Conjugated With Anti-CD22 Mabs: A Novel Targeted Delivery System for Lymphoma Treatment With Cardiopulmonary Avoidance. Oncotarget (2017) 8(35):58322-37. doi: 10.18632/oncotarget.16871

321. Moore RA, Adel N, Riedel E, Bhutani M, Feldman DR, Tabbara NE, et al. High Incidence of Thromboembolic Events in Patients Treated With 
Cisplatin-Based Chemotherapy: A Large Retrospective Analysis. J Clin Oncol (2011) 29(25):3466-73. doi: 10.1200/JCO.2011.35.5669

322. Barni S, Labianca R, Agnelli G, Bonizzoni E, Verso M, Mandala M, et al. Chemotherapy-Associated Thromboembolic Risk in Cancer Outpatients and Effect of Nadroparin Thromboprophylaxis: Results of a Retrospective Analysis of the PROTECHT Study. J Transl Med (2011) 9:179. doi: 10.1186/1479-5876-9-179

323. Radziwon-Balicka A, Medina C, O’Driscoll L, Treumann A, Bazou D, Inkielewicz-Stepniak I, et al. Platelets Increase Survival of Adenocarcinoma Cells Challenged With Anticancer Drugs: Mechanisms and Implications for Chemoresistance. Br J Pharmacol (2012) 167(4):787-804. doi: 10.1111/ j.1476-5381.2012.01991.x
Conflict of Interest: The authors declare that the research was conducted in the absence of any commercial or financial relationships that could be construed as a potential conflict of interest.

Copyright $\odot 2021$ Braun, Anders, Gudermann and Mammadova-Bach. This is an open-access article distributed under the terms of the Creative Commons Attribution License (CC BY). The use, distribution or reproduction in other forums is permitted, provided the original author(s) and the copyright owner(s) are credited and that the original publication in this journal is cited, in accordance with accepted academic practice. No use, distribution or reproduction is permitted which does not comply with these terms. 